\title{
Transport Characteristics Across Drum Filter Vents and Polymer Bags
}

Kevin J. Liekhus

Published August 1994

Idaho National Engineering Laboratory

EG\&G Idaho, Inc. Idaho Falls, Idaho 83415

Prepared for the

U.S. Department of Energy, Assistant Secretary fof

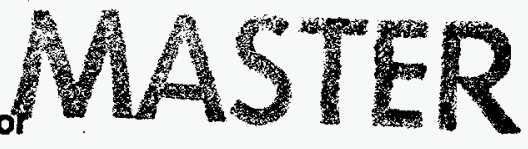
Environmental Restoration and Waste Management Under DOE Idaho Operations Office Contract DE-AC07-76ID01570 


\section{DISCLAIMER}

This report was prepared as an account of work sponsored by an agency of the United States Government. Neither the United States Government nor any agency thereof, nor any of their employees, make any warranty, express or implied, or assumes any legal liabiiity or responsibitity for the accuracy, completeness, or usefulness of any information, apparatus, product, or process disclosed, or represents that its use would not infringe privately owned rights. Reference herein to any specific commercial product, process, or service by trade name, trademark, manufacturer, or otherwise does not necessarily constitute or imply its endorsement, recommendation, or favoring by the United States Government or any agency thereof. The views and opinions of authors expressed herein do not necescarily state or reflect those of the United States Government or any agency thereof. 


\section{DISCLAIMER}

Portions of this document may be illegible electronic image products. Images are produced from the best available original document. 


\section{ABSTRACT}

The rate at which hydrogen $\left(\mathrm{H}_{2}\right)$ or a volatile organic compound (VOC) exits a layer of confinement in a vented waste drum is proportional to the concentration difference across the layer. The proportionality constant is the gas transport characteristic. A series of transport experiments were conducted to determine $\mathrm{H}_{2}$ and VOC transport characteristics across different drum filter vents and polymer bags. This report reviews the methods and results of past investigators in defining transport characteristics across filter vents and polymer bags, describes the apparatus and procedures used in these experiments, compares the reported and estimated transport characteristics with earlier results, and discusses the impact of changing the transport characteristic values used in model calculations. 


\section{SUMMARY}

This report reviews the methods and results of past investigators in defining hydrogen $\left(\mathrm{H}_{2}\right)$ and volatile organic compound (VOC) transport characteristics across drum filter vents and polymer bags, describes the apparatus and procedures used in experiments performed at the Idaho National Engineering Laboratory (INEL) to quantify transport characteristics across drum filter vents and polymer bags, compares the reported and estimated transport characteristics with earlier results, and discusses the impact of changing transport characteristic values in model calculations.

A review of experiments conducted to measure $\mathrm{H}_{2}$ and VOC diffusion characteristics across drum filter vents identified a wide variety of test vessel designs. In most cases, insufficient care was taken to minimize concentration gradient formation inside the test vessel. A series of filter vent diffusion tests were conducted at the INEL using a test vessel specifically designed to ensure that the assumption of uniform gas concentration in the test volume was valid. A cylindrical stainless steel vessel with a flat lid and base was designed to have a drum filter vent screwed in the center of the top lid. Separate side ports allowed for the introduction of gas and the sample collection with a gas-tight syringe. Because of variations in the filter housing assemblies, two different test vessels with internal volume between 55 and $60 \mathrm{~cm}^{3}$ were constructed. The $\mathrm{H}_{2}$ and VOC diffusion characteristics of NFT-012, NFT-013, and NFT-020 drum filter vents were determined. Pure hydrogen gas was used in the $\mathrm{H}_{2}$ diffusion characteristic experiments. Two different gas mixtures-each containing 5 VOCs-were used in the VOC diffusion characteristic measurements. Each VOC concentration was between about 100 and $1,000 \mathrm{ppm}$. The gas mixture was introduced into a test vessel at a rate of $1,000 \mathrm{~cm}^{3} \mathrm{~min}^{-1}$ for one minute to purge the vessel. Samples were withdrawn by gas syringe at regular time intervals and injected into a gas chromatograph to determine gas concentrations.

Multivariable two-level experiments with one replicate were designed to investigate the effect of bag closure type on $\mathrm{H}_{2}$ and VOC transport from small polymer bags. Polyethylene and polyvinyl chloride (PVC) bags with heat-sealed or taped closures were prepared. In preparing the bags with taped closures, an effort was made to ensure that the surface area was the same as for the heat-sealed bags. Trichloroethylene (TCE) and 1,1,2-trichloro-1,2,2-trifluoroethane (Freon-113) were used in the experiments.

Filter vent diffusion test results confirmed that test vessel configuration affects the calculated gas diffusion characteristic. Hydrogen diffusion characteristics calculated from experimental data using the INEL test vessels were about 10 to $25 \%$ greater than the highest previously reported values. In the TRUPACT-II safety analysis report (SAR), a hydrogen diffusion characteristic of $19 \times 10^{-7} \mathrm{~mol} \mathrm{~s}^{-1}$ was used to calculate the maximum allowable decay heat limit per innermost layer of confinement. This value was the lowest value determined across six NFT-012 drum filter vents. However, NFT-012 drum filter vents are no longer used in the transportation of vented waste drums. The NFT-013 and NFT-020 drum filter vents are currently used in waste drum transshipment. The lowest $\mathrm{H}_{2}$ diffusion characteristic measured for these drum filter vents using the INEL test vessels was $41 \times 10^{-7} \mathrm{~mol} \mathrm{~s}^{-1}$. The use of a $\mathrm{H}_{2}$ diffusion characteristic of a different drum filter vent will have a far more significant impact on model results than higher values resulting from improved test vessel design and experimental procedure. A larger $\mathrm{H}_{2}$ diffusion characteristic would result in a higher minimum allowable decay heat limit. 
Results from unsteady-state experiments indicated that the $\mathrm{H}_{2}$ transport characteristic for polymer bags with a taped closure was not significantly greater than for similar bags with no taped closure. Tests on PVC bags with a surface area between 2,000 and $3,000 \mathrm{~cm}^{2}$ and bag thickness between 2.8 and $3.0 \times 10^{-2} \mathrm{~cm}(11-12 \mathrm{mil})$ show that the $\mathrm{H}_{2}$ transport from bags with a taped closure was only 20 to $30 \%$ greater than from heat-sealed bags. The relative percentage increase in the $\mathrm{H}_{2}$ transport characteristic for bags with a taped closure compared to similar heat-sealed bags will decrease further with increasing bag surface area or decreasing bag thickness. Tests on polyethylene bags with a surface area of $2,000 \mathrm{~cm}^{2}$ and bag thickness of $7.6 \times 10^{-3} \mathrm{~cm}(3 \mathrm{mil})$ showed no difference at all in the $\mathrm{H}_{2}$ transport characteristic for bags with different types of closure. Under these conditions, $\mathrm{H}_{2}$ transport from small polymer bags was not significantly affected by the type of bag closure. This means that most small bags placed in vented waste drums could have either a taped closure or heat seal without significantly affecting $\mathrm{H}_{2}$ transport from the bags. It was similarly concluded that gas transport from polymer bags containing TCE or Freon-113 in actual waste drums would not be significantly affected by bag closure type.

In model calculations in the TRUPACT-II SAR of the maximum allowable decay heat limit per layer of confinement, a $\mathrm{H}_{2}$ transport characteristic of $5.60 \times 10^{-7} \mathrm{~mol} \mathrm{~s}^{-1}$ had been used to estimate gas transport from a polymer bag with a taped closure. This value reported in the TRUPACT-II SAR was the difference of two $\mathrm{H}_{2}$ transport characteristics measured across PVC bags with and without taped closures. Review of the original data indicates that the transport characteristic for at least one bag was not measured under steady-state conditions, as assumed. In addition, two unsteady-state experiments demonstrated that total $\mathrm{H}_{2}$ transport across a small PVC bag with a taped closure is not significantly greater than a similarly sized PVC bag with no taped closure. The maximum allowable decay heat limit should have been calculated using the $\mathrm{H}_{2}$ permeation characteristic reported in the TRUPACT-II SAR for a heat-sealed PVC bag which was $4.94 \times 10^{-7} \mathrm{~mol} \mathrm{~s}^{-1}$. This transport characteristic is $12 \%$ less than the value used in original calculations and would result in a slightly lower calculated decay heat limit, all other variables remaining the same. The average $\mathrm{H}_{2}$ permeation characteristic across heat-sealed PVC bags measured in the INEL transport experiments was $2.04 \times 10^{-7} \mathrm{~mol} \mathrm{~s}^{-1}$ and was less than the transport characteristic reported in the TRUPACT-II SAR because of smaller bag surface area.

The VOC diffusion characteristic across a filter vent is used in the Waste Isolation Pilot Plant (WIPP) no-migration determination (NMD) variance petition to estimate the rate of VOC emissions from a vented drum. The diffusion characteristics for carbon tetrachloride and 1,1,1-trichloroethane across different drum filter vent types listed in the WIPP NMD variance petition were on the order of $10^{-11} \mathrm{~mol} \mathrm{~s}^{-1}$. The explanation offered for the lower than expected VOC transport characteristics was a complex combination of Fickian and surface diffusion. A more likely explanation is that the experimental set-up resulted in significant concentration gradient across the test vessel volume. Several transport experiments, including one performed at the INEL, measured VOC diffusion characteristics on the order of $10^{-7} \mathrm{~mol} \mathrm{~s}^{-1}$. This is approximately four orders of magnitude greater and significantly affects the calculation of the total anticipated VOC emissions from vented waste drums at the WIPP facility. 


\section{CONTENTS}

ABSTRACT $\ldots \ldots \ldots \ldots \ldots \ldots \ldots \ldots \ldots \ldots \ldots \ldots \ldots \ldots \ldots \ldots \ldots \ldots \ldots \ldots \ldots \ldots \ldots$ iii

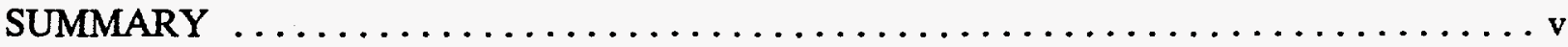

ACRONYMS $\ldots \ldots \ldots \ldots \ldots \ldots \ldots \ldots \ldots \ldots \ldots \ldots \ldots \ldots \ldots \ldots \ldots \ldots \ldots \ldots \ldots$

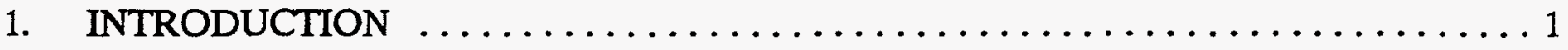

2. TRANSPORT CHARACTERISTICS $\ldots \ldots \ldots \ldots \ldots \ldots \ldots \ldots \ldots \ldots \ldots \ldots \ldots \ldots \ldots \ldots$

3. PREVIOUS TRANSPORT CHARACTERISTIC MEASUREMENTS $\ldots \ldots \ldots \ldots \ldots 4$

$3.1 \quad$ Drum Filter Vents $\ldots \ldots \ldots \ldots \ldots \ldots \ldots \ldots \ldots \ldots \ldots \ldots \ldots \ldots \ldots$

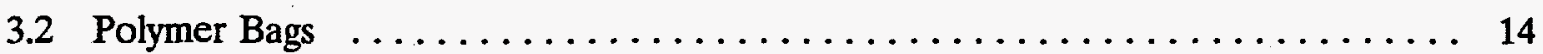

4. NEW TRANSPORT CHARACTERISTIC MEASUREMENTS $\ldots \ldots \ldots \ldots \ldots \ldots$

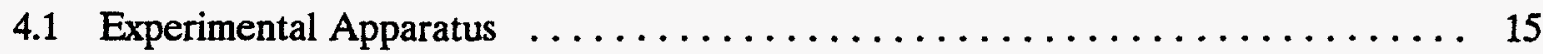

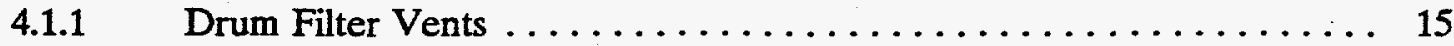

4.1.2 Polymer Bags $\ldots \ldots \ldots \ldots \ldots \ldots \ldots \ldots \ldots \ldots \ldots \ldots \ldots \ldots \ldots \ldots \ldots \ldots \ldots, 15$

4.2 Experimental Procedure $\ldots \ldots \ldots \ldots \ldots \ldots \ldots \ldots \ldots \ldots \ldots \ldots \ldots \ldots \ldots$

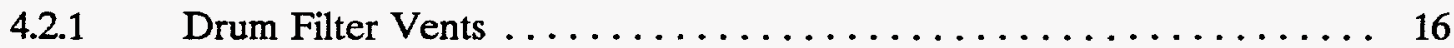

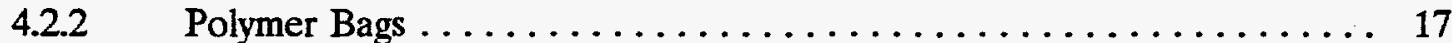

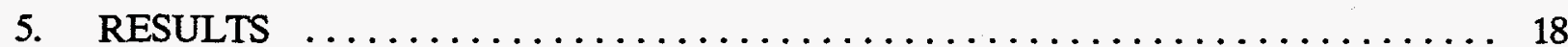

5.1 Hydrogen Transport Characteristics $\ldots \ldots \ldots \ldots \ldots \ldots \ldots \ldots \ldots \ldots \ldots, 18$

5.2 VOC Transport Characteristics $\ldots \ldots \ldots \ldots \ldots \ldots \ldots \ldots \ldots \ldots \ldots \ldots, 18$

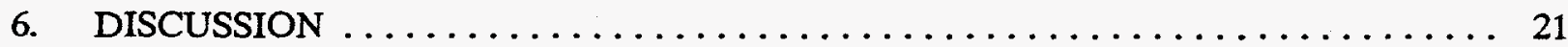

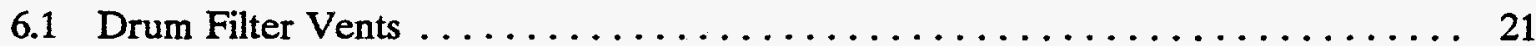

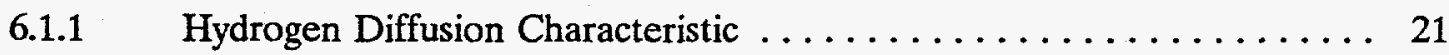

6.1.2 VOC Diffusion Characteristic $\ldots \ldots \ldots \ldots \ldots \ldots \ldots \ldots \ldots \ldots . \ldots \ldots$

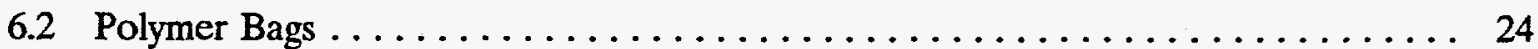

7. IMPACT OF TRANSPORT CHARACTERISTICS ON MODEL CALCULATIONS . 26 
7.1 Hydrogen Transport Characteristics $\ldots \ldots \ldots \ldots \ldots \ldots \ldots \ldots \ldots \ldots \ldots \ldots$

7.2 VOC-Filter Vent Diffusion Characteristic $\ldots \ldots \ldots \ldots \ldots \ldots \ldots \ldots$

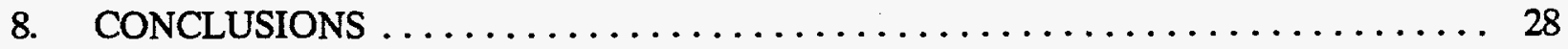

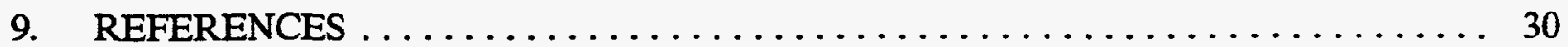

\section{FIGURES}

1. Schematic of NFT-012 filter vent (a) cross-section; (b) top $\ldots \ldots \ldots \ldots \ldots \ldots \ldots$

2. Schematic of NFT-013 filter vent (a) cross-section; (b) top $\ldots \ldots \ldots \ldots \ldots \ldots \ldots$

3. Schematic of NFT-020 filter vent (a) cross-section; (b) top $\ldots \ldots \ldots \ldots \ldots \ldots \ldots \ldots$

4. Schematic of experimental set-up used at Westinghouse to determine hydrogen diffusion characteristic across NFT filter vents $\ldots \ldots \ldots \ldots \ldots \ldots$

5. Schematic of experimental test vessel used at Westinghouse to determine VOC diffusion characteristics across NFT filter vents $\ldots \ldots \ldots \ldots \ldots \ldots \ldots$

6. Schematic of experimental set-up used to determine VOC diffusion characteristics reported in the WIPP NMD variance petition $\ldots \ldots \ldots \ldots \ldots \ldots \ldots$

7. Schematic of experimental test vessel used at Westinghouse to determine $\mathrm{H}_{2}$ diffusion characteristics across NFT filter vents $\ldots \ldots \ldots \ldots \ldots \ldots \ldots \ldots \ldots \ldots \ldots$

8. Schematic of test vessels used at the INEL to determine $\mathrm{H}_{2}$ diffusion characteristic across NFT-020 filter vents (a) original design;

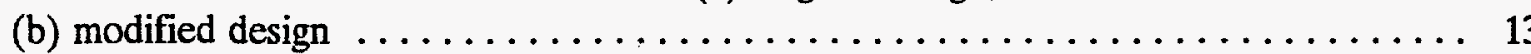

\section{TABLES}

1. Average and minimum $\mathrm{H}_{2}$ diffusion characteristics $\left(\mathrm{mol} \mathrm{s}^{-1} \times 10^{7}\right)$ across different NFT drum filter vents $\ldots \ldots \ldots \ldots \ldots \ldots \ldots \ldots \ldots \ldots \ldots \ldots \ldots \ldots \ldots$

2. Hydrogen transport characteristics $\left(\mathrm{mol} \mathrm{s}^{-1} \times 10^{7}\right)$ for polyethylene and

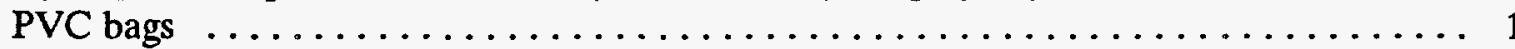

3. VOC diffusion characteristics $\left(\mathrm{mol} \mathrm{s}^{-1} \times 10^{7}\right)$ for clean and used NFT-020 drum

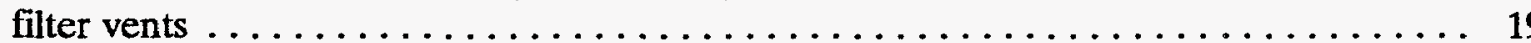


4. VOC diffusion characteristic ( $\mathrm{mol} \mathrm{s}^{-1} \times 10^{7}$ ) for NFT-012 and NFT-013 drum filter vents

5. Comparison of reported $\mathrm{H}_{2}$ diffusion characteristics $\left(\mathrm{mol} \mathrm{s}^{-1} \times 10^{7}\right.$ ) for different drum filter vents

6. Experimental and estimated $\mathrm{VOC} / \mathrm{H}_{2}$ diffusion characteristic ratios $\ldots \ldots \ldots 23$

7. Ratio of average $\mathrm{H}_{2}$ transport characteristic for bags with taped closures to average $\mathrm{H}_{2}$ transport characteristic for heat-sealed bags 


\section{ACRONYMS AND ABREVIATIONS}

$\begin{array}{ll}\text { Freon-113 } & \text { 1,1,2-trichloro-1,2,2-trifluoroethane } \\ \text { GC } & \text { gas chromatograph } \\ \mathrm{H}_{2} & \text { hydrogen } \\ \text { INEL } & \text { Idaho National Engineering Laboratory } \\ \text { NFT } & \text { Nuclear Filter Technology } \\ \text { NMD } & \text { no-migration determination } \\ \text { RFP } & \text { Rocky Flats Plant } \\ \text { SRP } & \text { Savannah River Plant } \\ \text { STP } & \text { standard temperature and pressure } \\ \text { TCA } & \text { trichloroethane } \\ \text { TCE } & \text { trichloroethylene } \\ \text { SAR } & \text { safety analysis report } \\ \text { VOC } & \text { volatile organic compound } \\ \text { WIPP } & \text { Waste Isolation Pilot Plant }\end{array}$




\section{Transport Characteristics Across Drum Filter Vents and Polymer Bags}

\section{INTRODUCTION}

The rate at which hydrogen $\left(\mathrm{H}_{2}\right)$ or a volatile organic compound (VOC) exits a layer of confinement in a vented waste drum is proportional to the concentration difference across the layer. The proportionality constant is the gas transport characteristic. Gas permeates through polymer bags or diffuses through openings in the layer boundary. The gas transport characteristic is the product of the gas transport property, such as permeability or diffusivity, and surface area divided by a characteristic length. Knowledge of the $\mathrm{H}_{2}$ transport characteristics across drum filter vents and polymer bags was used in the safety analysis report for the TRUPACT-II Shipping Package (TRUPACT-II SAR) to calculate the maximum allowable decay heat limit per innermost confinement layer to ensure that the hydrogen concentration in payload materials does not exceed $5 \%$ by volume. ${ }^{1}$ Knowledge of VOC transport characteristics is important in estimating VOC emission rates from vented waste drums ${ }^{2}$ and VOC concentrations in the void volumes of a waste drum. 3,4

Several investigators have measured $\mathrm{H}_{2}$ and VOC transport characteristics across filter vents and polymer bags. All drum filter vent diffusion experiments used test vessels with different volumes and dimensions. Different experiments investigating $\mathrm{H}_{2}$ transport from sealed polymer bags reached opposite conclusions whether gas transport across a taped closure was significantly greater than across a heat-sealed closure. The differences in reported values resulting from variations in test apparatus and procedures raise questions as to which values should be used in calculations concerning decay heat limits, total emissions rate, and other health and safety issues. A series of experiments was conducted at the Idaho National Engineering Laboratory (INEL) to measure $\mathrm{H}_{2}$ and VOC transport characteristics across drum filter vents and polymer bags. The experiments were designed to address past discrepancies in the test vessel configuration and test procedures.

This report reviews the methods and results of past investigators in defining transport characteristics across filter vents and polymer bags, describes the apparatus and procedures used in a new set of transport experiments, compares the reported and estimated transport characteristics with earlier results, and discusses the impact of changing the transport characteristic values in model calculations. First, mathematical definitions of the transport characteristics are presented. Second, transport characteristics reported in earlier studies are reviewed with particular attention given to the experimental apparatus and procedures used. The report then describes experimental apparatus and test procedures used in the most recent INEL transport experiments to determine $\mathrm{H}_{2}$ and VOC transport characteristics across different filter vents and polymers. Experimental test apparatus, procedures, and results from these experiments are compared with those described in earlier experiments. In addition, methods of estimating VOC diffusion characteristic across filter vents are examined. Finally, the implications of using these new $\mathrm{H}_{2}$ and VOC transport characteristics in model calculations related to health and safety issues are discussed. 


\section{TRANSPORT CHARACTERISTICS}

The primary mechanisms for gas transport from the void volume inside a layer of confinement with a polymer boundary are permeation across the polymer, diffusion across an opening in the boundary, and gas accumulation in the boundary as the result of the gas solubility in the polymer. The total unsteady-state gas transport rate is defined by summing the contribution of each transport mechanism

$$
V c \frac{d\left(\Delta y_{p}\right)}{d t}=-\left(\frac{\phi \odot A_{p} P}{x_{p}}+\frac{D A_{d}}{x_{d}}\right) c \Delta y_{p}-V_{p} \frac{d s}{d t}
$$

where

$$
\begin{aligned}
& \mathrm{V}=\text { void volume confined by polymer, } \mathrm{cm}^{3} \\
& \text { c }=\text { total gas concentration, } \mathrm{mol} \mathrm{cm} \mathrm{cm}^{-3} \\
& \Delta y_{p}=\text { gas mole fraction difference across polymer } \\
& \mathrm{t}=\text { time, } \mathrm{s} \\
& \phi \quad=\quad 76 \mathrm{~T} /(273.15 \mathrm{P}) \\
& \mathrm{T}=\text { temperature, } \mathrm{K} \\
& \mathrm{P} \quad=\quad \text { pressure, } \mathrm{cm} \mathrm{Hg} \\
& \rho=\text { gas permeability coefficient, } \mathrm{cm}^{3}(\mathrm{STP}) \mathrm{cm} \mathrm{cm}^{-2}(\mathrm{~cm} \mathrm{Hg})^{-1} \mathrm{~s}^{-1} \\
& A_{p}=\text { polymer surface area across which VOC permeates, } \mathrm{cm}^{2} \\
& \mathrm{x}_{\mathrm{p}}=\text { polymer thickness, } \mathrm{cm} \\
& \mathrm{D}=\text { gas diffusivity in air, } \mathrm{cm}^{2} \mathrm{~s}^{-1} \\
& A_{d}=\text { cross-sectional area of opening across polymer boundary, } \mathrm{cm}^{2} \\
& \mathrm{x}_{\mathrm{d}}=\text { diffusional length across opening, } \mathrm{cm} \\
& \mathrm{V}_{\mathrm{p}}=\text { volume of polymer boundary, } \mathrm{cm}^{3} \text { polymer } \\
& \mathrm{s}=\text { gas concentration in polymer, } \mathrm{cm}^{3} \text { gas } \mathrm{cm}^{-3} \text { polymer. }
\end{aligned}
$$

In the case where the gas concentration in the polymer has reached a near-constant value, the gas transport rate is the sum of the transport rates via permeation and diffusion 


$$
V c \frac{d\left(\Delta y_{p}\right)}{d t}=-\left(\frac{\phi \odot A_{p} P}{x_{p}}+\frac{D A_{d}}{x_{d}}\right) c \Delta y_{p} .
$$

The total gas concentration is defined by the ideal gas law

$$
c=\frac{P}{R T}
$$

where $\mathrm{R}$ is the gas constant and equals $6236.6 \mathrm{~cm}^{3}(\mathrm{~cm} \mathrm{Hg}) \mathrm{mol}^{-1} \mathrm{~K}^{-1}$. Combining Equations (2) and (3) yields

$$
V c \frac{d\left(\Delta y_{p}\right)}{d t}=-\left(K_{p}+K_{d}\right) \Delta y_{p}
$$

where

$$
\begin{aligned}
& \mathrm{K}_{\mathrm{p}}=\text { permeation characteristic, } 4.46 \times 10^{-5} \mathrm{PA}_{\mathrm{p}} \mathrm{P} \mathrm{x}_{\mathrm{p}}^{-1}, \mathrm{~mol} \mathrm{~s}^{-1} \\
& \mathrm{~K}_{\mathrm{d}}=\text { diffusion characteristic, } \mathrm{DA}_{\mathrm{d}} \mathrm{P}\left(\mathrm{RTx}_{\mathrm{d}}\right)^{-1}, \mathrm{~mol} \mathrm{~s}^{-1} .
\end{aligned}
$$

Solving Equation (4), the gas mole fraction difference is a function of time

$$
\ln \left(\frac{\Delta y_{p}}{\Delta y_{p, 0}}\right)=-\frac{\left(K_{p}+K_{d}\right)}{V c}\left(t-t_{0}\right) .
$$

Plotting $\ln \left(\Delta \mathrm{y}_{\mathrm{p}} / \Delta \mathrm{y}_{\mathrm{p}, 0}\right)$ versus ( $\left.\mathrm{t}-\mathrm{t}_{0}\right)$ yields a straight line with a slope defined by Equation (5).

The unsteady-state rate of gas transport across a filter vent is defined as

$$
V c \frac{d\left(\Delta y_{f}\right)}{d t}=-D^{*} \Delta y_{f}
$$

where

$$
\begin{aligned}
& D^{*}=\text { gas filter vent diffusion characteristic, mol s } \\
& \Delta y_{\mathrm{f}}=\text { gas mole fraction difference across filter vent. }
\end{aligned}
$$

In the case of steady-state transport, the gas transport rates across all layers of confinement, including the filter vent, are equal to a constant rate $r$

$$
r=\left(K_{p}+K_{d}\right) \Delta y_{p}=D^{*} \Delta y_{f}
$$




\section{PREVIOUS TRANSPORT CHARACTERISTIC MEASUREMENTS}

This section summarizes the reported transport characteristics across drum filter vents and polymer bags from earlier investigations. Discussion is focused on the experimental apparatus and test procedures that may have affected the calculated transport characteristics.

\subsection{Drum Filter Vents}

Hydrogen or VOC diffusion characteristics across different filter vent types have been reported by a number of investigators. Three filter vent types studied, which contained a carboncomposite filter, were manufactured by Nuclear Filter Technology. Filter vent NFT-012, shown in Figure 1, was initially used at the Rocky Flats Plant (RFP). Filter vent NFT-013, shown in Figure 2, is now used at the RFP and the Savannah River Plant (SRP) in waste drums prepared for transshipment. The NFT-013 filter vent is an adaptation of the NFT-012; the NFT-013 has larger openings in the bottom and top of the filter housing assembly. The changes in the filter assembly were designed to increase the overall hydrogen diffusion characteristic across the filter vent. The NFT-020 filter vent, shown in Figure 3, is used at the INEL.

Peterson ${ }^{\mathrm{a}}$ determined hydrogen diffusion characteristics across carbon-composite filter vents identified as the types used at the RFP, the INEL, and the SRP. A schematic of the test vessel used to perform the diffusion experiments is shown in Figure 4. The test vessel volume was approximately $75 \mathrm{~cm}^{3}$. An adapter connecting the filter vent to the test vessel probably resulted in the development of a concentration gradient within the vessel. Peterson did not identify the types of filter vents other than by the site where they were used. This author believes that the RFP and INEL filters were NFT-012 and NFT-020, respectively. The SRP filter vents tested are not thought to be NFT-013 filter vents because of NFT-013 filter vent was not being made at the date of the tests. Experimental results yielded $\mathrm{H}_{2}$ diffusion characteristics across the NFT-012 and NFT-020 filter vents of $(23 \pm 2) \times 10^{-7} \mathrm{~mol} \mathrm{~s}^{-1}$ and $(39 \pm 10) \times 10^{-7} \mathrm{~mol} \mathrm{~s}^{-1}$, respectively.

The Waste Isolation Pilot Plant (WIPP) no-migration determination (NMD) variance petition $^{2}$ reported diffusion characteristics for carbon tetrachloride and 1,1,1-trichloroethane (TCA) across NFT filters on the order of $10^{-11} \mathrm{~mol} \mathrm{~s}^{-1}$. These values were approximately four orders of magnitude lower than values estimated using kinetic gas theory for ordinary diffusion. In a study by Peterson and Marshall, ${ }^{b}$ VOC diffusion characteristics on the order of $10^{-7}$ were reported. The test vessel used in their VOC diffusion experiments, shown in Figure 5, had a internal volume of $60 \mathrm{~cm}^{3}$ abd attempted to minimize the potential for concentration gradients in the system. The VOC diffused through the filter into another $60-\mathrm{cm}^{3}$ vessel with its lid removed. Peterson and Marshall assumed that this vessel configuration allowed sufficient convection to maintain the gas concentration immediately outside the filter at zero. They determined that the test vessel and gas sampling configuration in the earlier VOC diffusion study, shown in Figure 6, resulted in significant concentration gradients across the system. The average $\mathrm{H}_{2}$ diffusion

a. Unpublished research results of determination of hydrogen diffusion characteristics across different filter types; S. H. Peterson, Westinghouse R\&D Center, (July 1988).

b. Unpublished research results of VOC diffusion characteristics measurements across carbon-composite filters; S. H. Peterson and G. R. Marshall, Westinghouse R\&D Center (October 1990). 


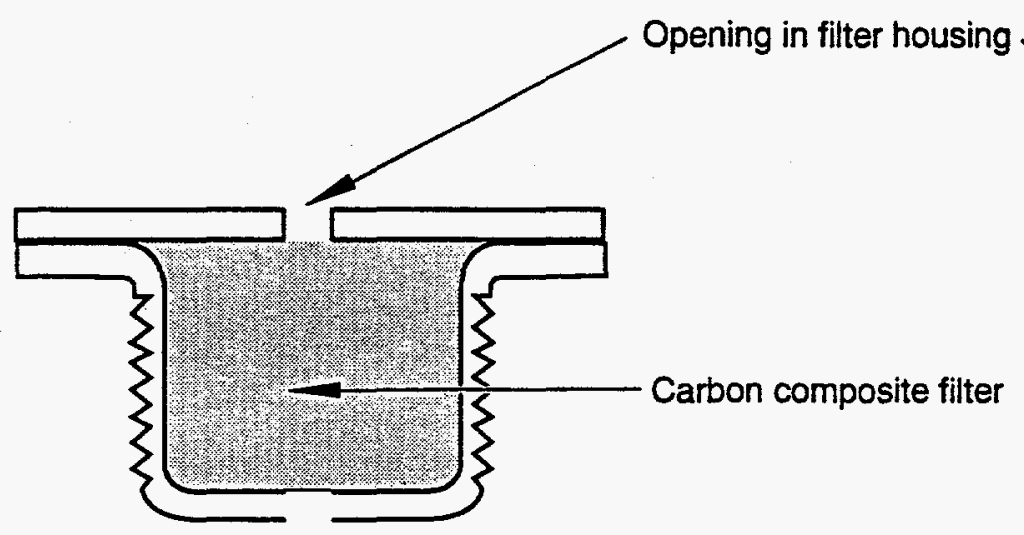

(a)

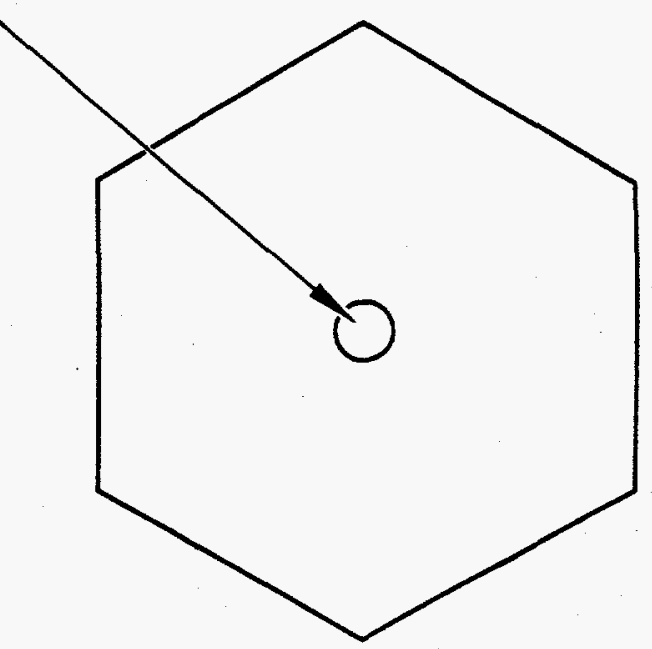

(b)

KL940003

Figure 1. Schematic of NFT-012 filter vent (a) cross-section; (b) top. 


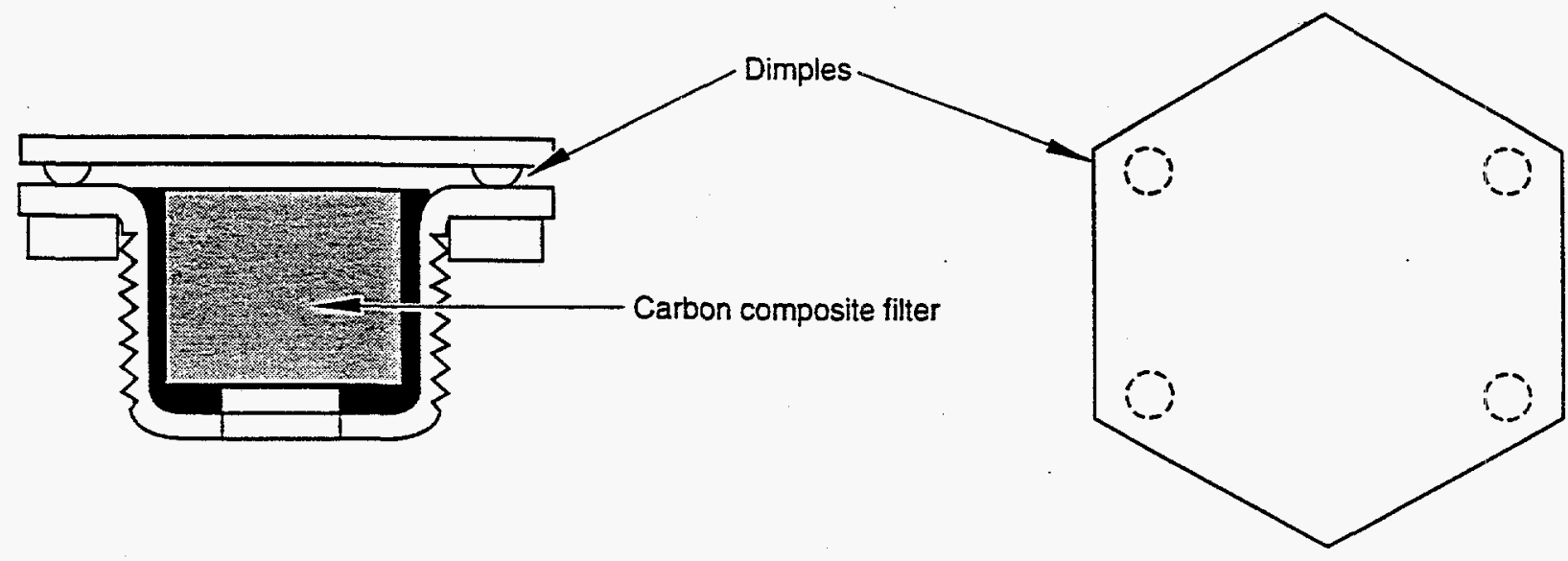

(a)

(b)

KL94 0002

Figure 2. Schematic of NFT-013 filter vent (a) cross-section; (b) top. 


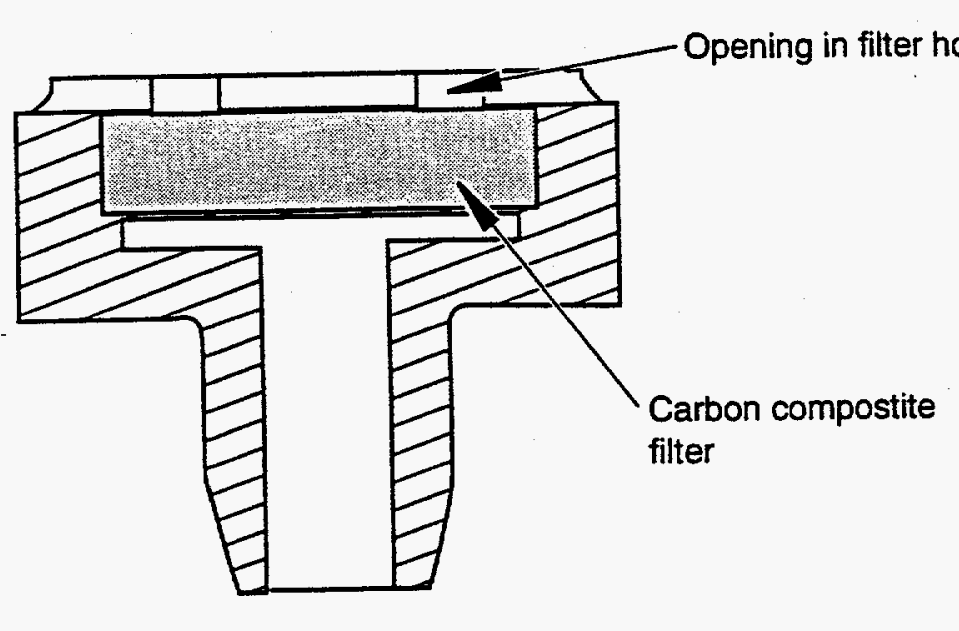

(a)

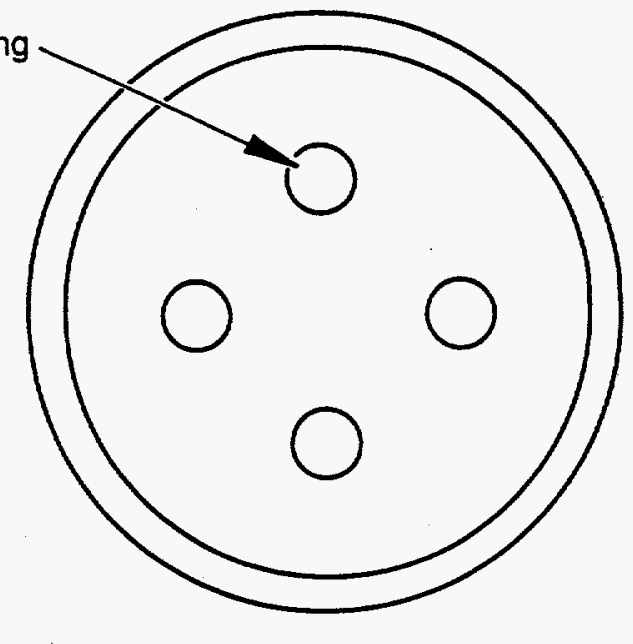

(b)

KL940004

Figure 3. Schematic of NFT-020 filter vent (a) cross-section; (b) top. 


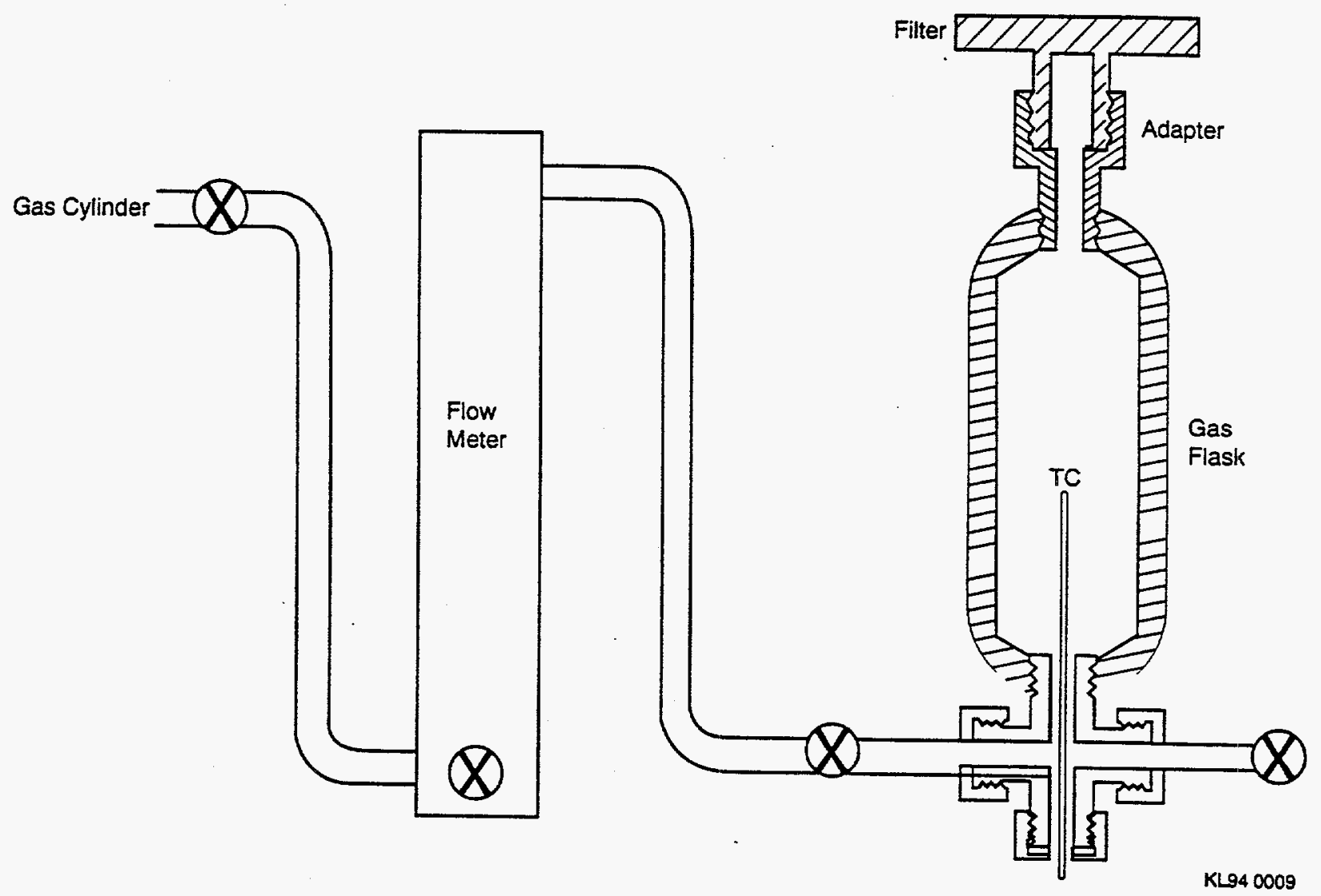

Figure 4. Schematic of experimental set-up used at Westinghouse to determine hydrogen diffusion characteristic across NFT filter vents (from unpublished research results of S. H. Peterson, Westinghouse R\&D Center, July 1988). 


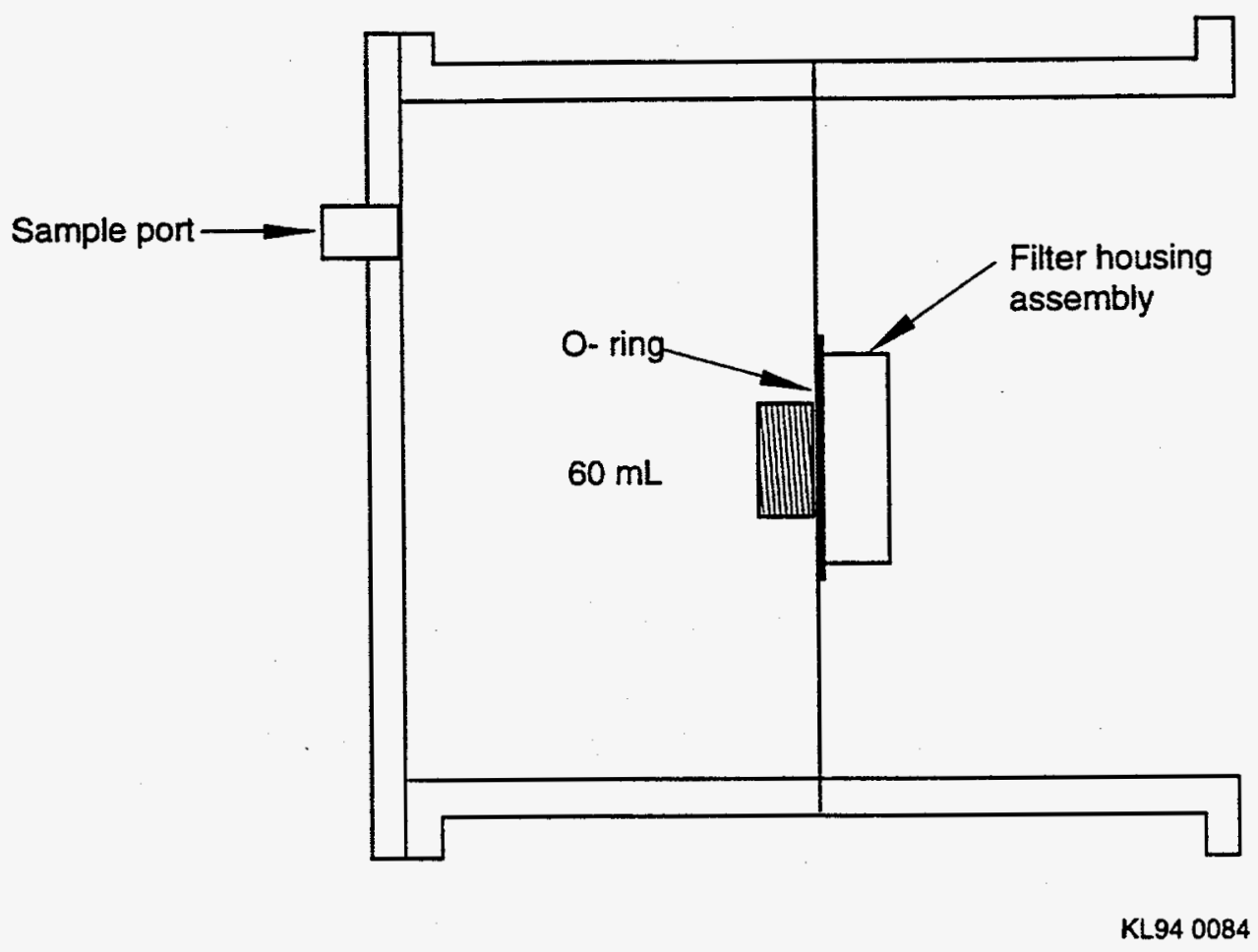

Figure 5. Schematic of experimental test vessel used at Westinghouse to determine VOC diffusion characteristics across NFT filter vents (from unpublished research result of S. $H$. Peterson and G. R. Marshall, Westinghouse R\&D Center, October 1990). 


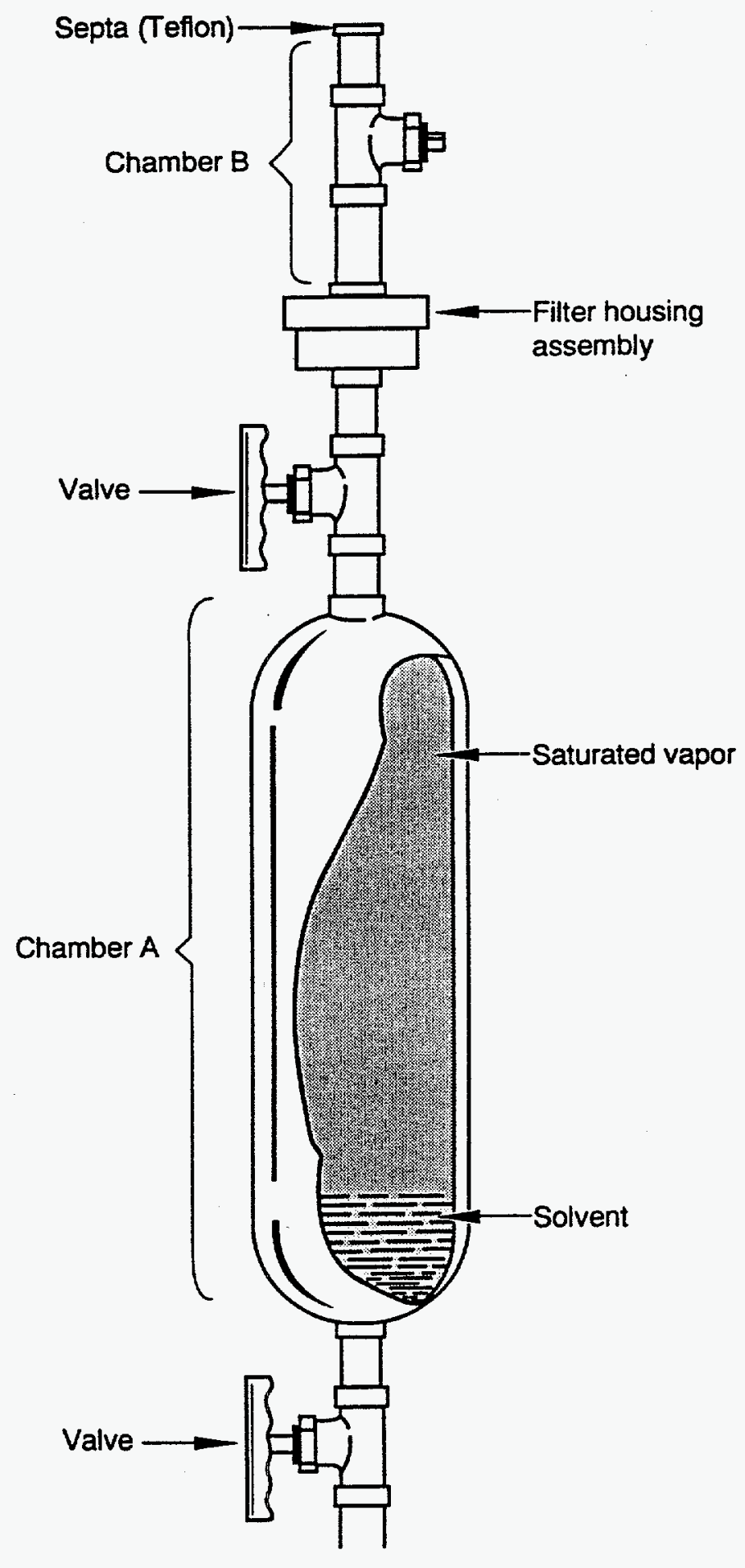

KL940008

Figure 6. Schematic of experimental set-up used to determine VOC diffusion characteristics reported in the WIPP NMD variance petition. ${ }^{2}$ 
characteristic for NFT-013 filter vents was determined to be $74 \times 10^{-7}$ mol s${ }^{-1}$ using a different test vessel shown in Figure 7. The test vessel had a volume of $110 \mathrm{~cm}^{3}$ with an approximate length of $20 \mathrm{~cm}$ and diameter of $3 \mathrm{~cm}$. In addition, the filter vent was attached using an adapter that probably resulted in a concentration gradient across the gas chamber.

Another set of diffusion experiments was performed across NFT-013 filter vents. ${ }^{c}$ The experimental equipment consisted of a 4.33- $\mathrm{L}$ container inside a larger vessel with a volume of 47.3 L. $\mathrm{A} \mathrm{H}_{2}$ gas mixture was introduced inside the smaller vessel. The $\mathrm{H}_{2}$ concentration was measured inside each vessel. Hydrogen diffused across the filter vent located on the smaller vessel. Data from these experiments were used to calculate $\mathrm{H}_{2}$ diffusion characteristics. ${ }^{d}$ The average $\mathrm{H}_{2}$ diffusion characteristic for five NFT-013 filter vents was $(105 \pm 3) \times 10^{-7} \mathrm{~mol} \mathrm{~s} \mathrm{~s}^{-1}$. The hydrogen diffusion characteristic was determined for four NFT-013 filter vents using a 1.5-1 test vessel. $^{5}$ The sample port was located near the top of the vessel to minimize its distance from the filter. The average value reported was $(85 \pm 3) \times 10^{-7} \mathrm{~mol} \mathrm{~s}^{-1}$.

A series of diffusion experiments was conducted that demonstrated the importance of the test vessel configuration on the calculated diffusion characteristic. The average $\mathrm{H}_{2}$ diffusion characteristic for NFT-020 filter vents in the first set of experiments, using a test vessel shown in Figure $8 \mathrm{a}$, was $(24 \pm 3) \times 10^{-7} \mathrm{~mol} \mathrm{~s}^{-1}$. ${ }^{\mathrm{e}}$ A modified test vessel configuration, shown in Figure $8 \mathrm{~b}$, reduced the distance between the filter vent and the vessel base. ${ }^{\mathrm{f}}$ The average $\mathrm{H}_{2}$ diffusion characteristic for NFT-020 filter vents using the modified test vessel was $(40 \pm 2) \times 10^{-7} \mathrm{~mol} \mathrm{~s}^{-1}$. The increase in the reported diffusion characteristic was directly attributed to the test vessel modification.

The hydrogen diffusion characteristic across filter vents with sintered metal filters have been reported. ${ }^{g}$ The filter vents were manufactured by Pall Advanced Separation Systems. The test vessel shown in Figure $8 \mathrm{~b}$ was used in the diffusion tests. The average hydrogen diffusion characteristic for six filter vents comparable in size and dimensions to a NFT-020 filter vent was $(39 \pm 1) \times 10^{-7} \mathrm{~mol} \mathrm{~s}^{-1}$. The average hydrogen diffusion characteristic across two filter vents comparable in size and dimensions to a NFT-013 filter vent was $(256 \pm 45) \times 10^{-7} \mathrm{~mol} \mathrm{~s}^{-1}$. The large standard deviation was attributed to rapid transport from the test vessel which made it difficult to accurately reproduce experimental results.

c. Unpublished report evaluating hydrogen diffusion across filter vents; D. T. Hobbs, Westinghouse Savannah River Corp. (July 1990).

d. Unpublished report evaluating hydrogen and VOC diffusion characteristics across NFT-012 and NFT-013 filter vents; K. J. Liekhus and D. A. Johnson, EG\&G Idaho, Inc. (June 1994).

e. Unpublished research results concerning hydrogen diffusion characteristic measurements across NFT-020 filters; E. B. McNew and D. A. Johnson, EG\&G Idaho Inc. (April 1992).

f. Unpublished research results concerning measurements of hydrogen diffusion characteristic across NFT-020 filter vents; E. B. McNew, EG\&G Idaho Inc. (June 1992).

g. Unpublished research results reporting hydrogen diffusion characteristics measured across carbon composite and sintered metal filters; D. A. Johnson and K. Messick, EG\&G Idaho Inc. (May 1993). 


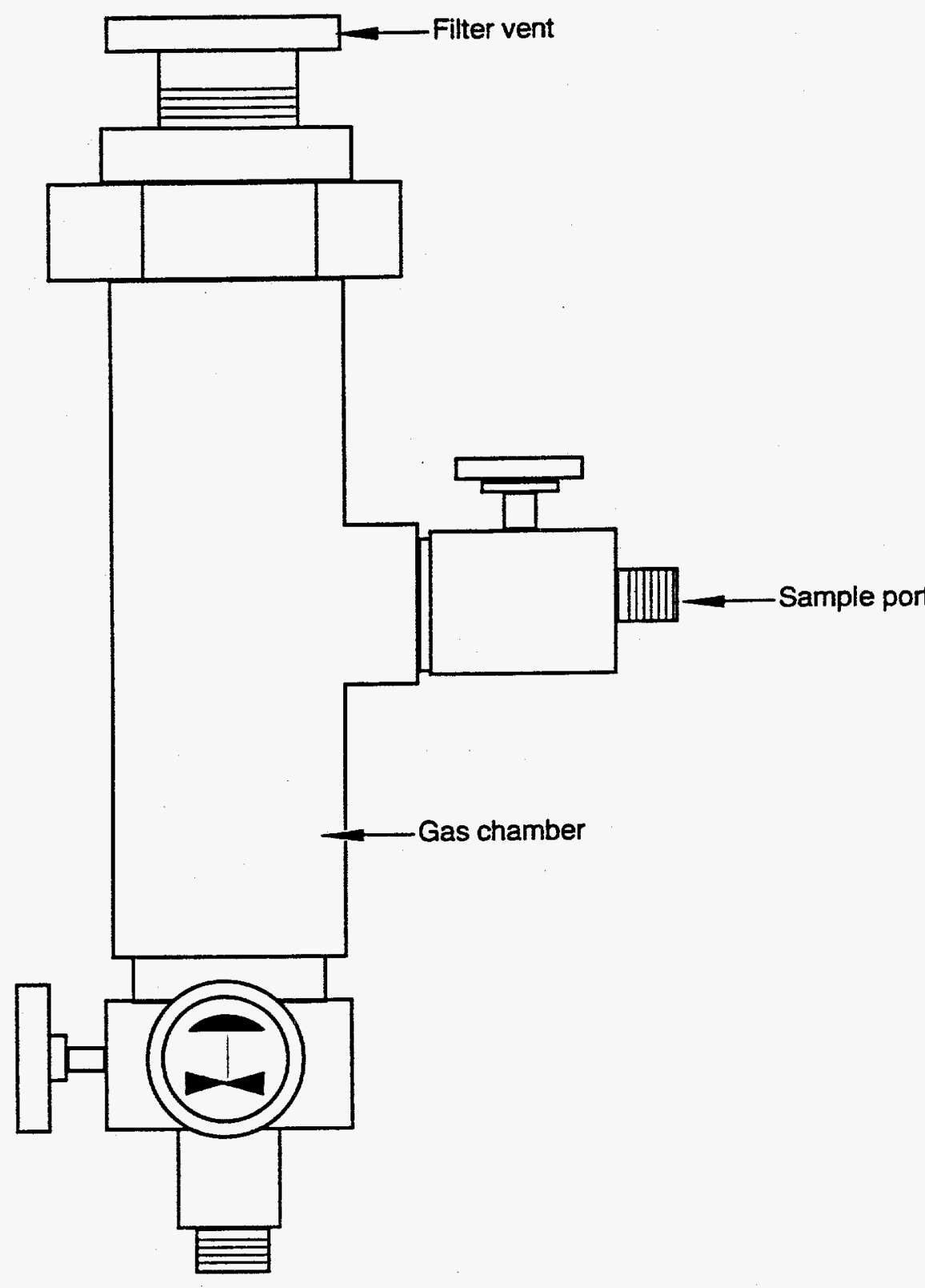

KL940006

Figure 7. Schematic of experimental test vessel used at Westinghouse to determine $\mathrm{H}_{2}$ diffusion characteristics across NFT filter vents (from unpublished research result of S. H. Peterson and G. R. Marshall, Westinghouse R\&D Center, October 1990). 


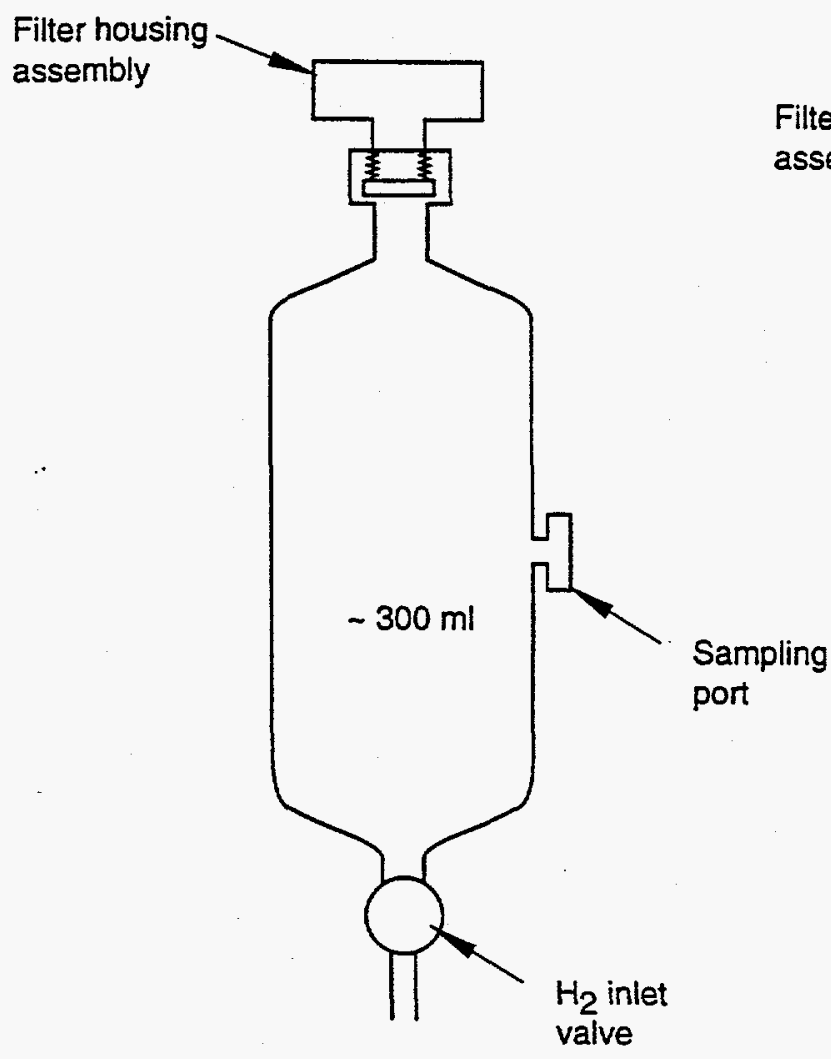

(a)

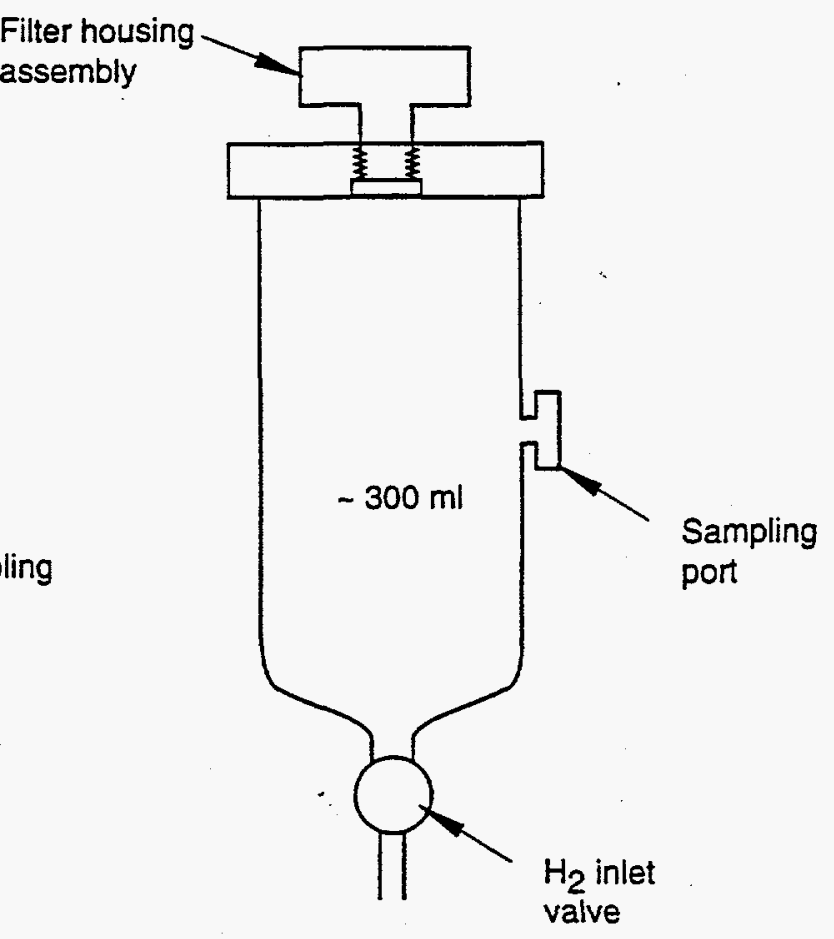

(b)

KL94 0005

Figure 8. Schematic of test vessels used at the INEL to determine $\mathrm{H}_{2}$ diffusion characteristic across NFT-020 filter vents (a) original design; (b) modified design (unpublished research results of E. B. McNew and D. A. Johnson, EG\&G Idaho, Inc., April 1992; E. B. McNew, EG\&G Idaho, Inc., June 1992). 


\subsection{Polymer Bags}

The gas diffusion characteristic across different filter vents of the same design will be similar, allowing for variations in construction. Equation (4) shows that the permeation characteristics of different polymer bags do not have to be similar because, besides being a function of the gaspolymer permeability, they are also a function of the permeable surface area and bag thickness. The permeable area is the parameter that can have the greatest variation and depends upon how much waste is placed inside the bag and the type of bag closure.

Hydrogen transport characteristics for different layers of confinement in vented waste drums have been determined under assumed steady-state conditions. ${ }^{1}$ The layers of confinement included polyethylene and polyvinyl chloride (PVC) bags as well as drum liners and drum filter vents. The polymer bags were sealed by a twist-and-tape or fold-and-tape method. The experiments consisted of simulating hydrogen generation by maintaining a controlled release of hydrogen gas in the innermost bag and monitoring the hydrogen concentration in all void volumes between the layers of confinement. The tests were terminated when it was determined that $\mathrm{H}_{2}$ concentrations in all layers of confinement remained constant for at least twelve hours. A hydrogen mass balance at steady state allowed calculation of the gas transport characteristic across each layer of confinement.

The hydrogen diffusion characteristic of a taped bag closure of a small PVC bag was calculated as the difference between the $\mathrm{H}_{2}$ transport characteristics of polymer bags with and without taped closures. A H $\mathrm{H}_{2}$ diffusion characteristic of $5.6 \times 10^{-7} \mathrm{~mol} \mathrm{~s}^{-1}$ was reported for a taped closure. A hydrogen permeation characteristic of $4.9 \times 10^{-7} \mathrm{~mol} \mathrm{~s}^{-1}$ was calculated for al $0.036-\mathrm{cm}(14-\mathrm{mil})$ PVC heat-sealed bag with a permeable surface area of approximately $5,800 \mathrm{~cm}^{3}$. The reported hydrogen flow rates into the bags at the time steady state was declared were not identical and ranged between 1.5 and $3.7 \mathrm{~cm}^{3} \mathrm{hr}^{-1}$. The gas feed rate was not maintained at a constant value but adjusted as necessary to maintain $\mathrm{H}_{2}$ concentration in the innermost bag at or near $4 \%$.

Two experiments were conducted to identify hydrogen diffusion characteristics for $0.030-\mathrm{cm}$ (12-mil) thick PVC bags with and without a taped closure. ${ }^{5}$ In the first test, a bag was sealed over a circular plate with a surface area of approximately $2,800 \mathrm{~cm}^{2}$ and a depth of approximately $2.5 \mathrm{~cm}$. The bag was filled to atmospheric pressure with a $6 \%$ hydrogen $/ 94 \%$ argon gas mixture. The plate was fitted with a sample port and samples were collected at regular intervals and analyzed by mass spectrometry. The hydrogen diffusion characteristic was calculated to be $2.8 \times 10^{-7} \mathrm{~mol} \mathrm{~s}^{-1}$. Another bag was prepared with a taped closure. The open end was twisted between 6 and 8 times, folded over so that the length of the twisted section end was halved, and then secured with tape wrapped around the folded material. The taped closure and sufficient bag material were removed and secured over the circular plate. Five different bags with a taped closure were prepared and tested. The average hydrogen diffusion characteristic across these samples was $3.6 \times 10^{-7} \mathrm{~mol} \mathrm{~s}^{-1}$. 


\section{NEW TRANSPORT CHARACTERISTIC MEASUREMENTS}

The review of earlier drum filter vent diffusion experiments showed a wide variety of test vessel designs. In most cases, insufficient care was taken to minimize concentration gradient formation within the test vessel. A series of diffusion tests was conducted at the INEL using a test vessel specifically designed to minimize development of concentration gradients. A series of transport experiments was also conducted to identify $\mathrm{H}_{2}$ and VOC transport characteristics across polymer bags and determine whether hydrogen transport across a small polymer bag with a taped closure is significant compared with permeation across the bag surface.

\subsection{Experimental Apparatus}

\subsubsection{Drum Filter Vents}

A cylindrical stainless steel vessel with a flat lid and base was constructed with an external diameter of $6.0 \mathrm{~cm}$ (2.4 in.) and an external height of $3.8 \mathrm{~cm}$ (1.5 in.). The vessel was designed for a drum filter vent to be screwed into the center of the top lid. Separate side ports allowed for the introduction of gas and the sample collection with a gas-tight syringe. Because of variations in the filter housing assemblies, two different test vessels were constructed. The internal volume of the test vessel used with NFT-012 and NFT-013 filter vents was $55 \mathrm{~cm}^{3}$ and for the test vessel used with NFT-020 filter vents was $59 \mathrm{~cm}^{3}$.

\subsubsection{Polymer Bags}

Polyethylene and PVC bags were heat-sealed or taped closed in a manner that ensured that the final surface area of the taped bags was approximately equal to that of the heat-sealed bags. The heat-sealed bags had a width of $30.5 \mathrm{~cm}$ (12 in.) and length of $33 \mathrm{~cm}$ (13 in.). The width of the taped bags was identical to that of the heat-sealed bags. The taped portion was approximately $15 \mathrm{~cm}$ ( 6 in.) long. Each bag held $3,750 \mathrm{~cm}^{3}$ of gas without making the bag surface taut which meant that the internal bag and ambient pressures were equal. The average thickness of the polyethylene bags was $7.6 \times 10^{-3} \mathrm{~cm}(3 \mathrm{mil})$ and of the PVC bags was $2.8 \times 10^{-2} \mathrm{~cm}(11 \mathrm{mil})$.

Bag feedthroughs were fabricated from modified brass bulkhead unions with two backing washers, two teflon sealing washers, and an n-butyl O-ring. The outer sealing washer was machined to allow the O-ring to seat between the sealing washer and bag. The outer backing washer and outer teflon sealing washer were epoxied to the body of the bulkhead union. The teflon ferrules were used to seal the sample transfer lines.

The transport experiments were performed on an automated lab-scale system ${ }^{3,4}$ that sampled and analyzed gas concentrations in the bags. The automated gas sampling system included a highand low-level gas sampling manifold, a gas chromatograph (GC) with flame ionization and thermal conductivity detectors, a GC data station, a 10-port gas sampling valve, a mechanical vacuum pump, a microcontroller, and a process controller. 


\subsection{Experimental Procedure}

In each experiment, the void volume of the filter vent test vessel or polymer bag was filled with a gas mixture and the average gas concentration was measured as a function of time. The rate of change in the gas concentration is directly dependent on the transport characteristic of the drum filter vent or polymer bag.

\subsubsection{Drum Filter Vents}

Pure hydrogen gas was used in the $\mathrm{H}_{2}$ diffusion characteristic experiments. Two different gas mixtures were used in the VOC diffusion characteristic measurements. A VOC-gas mixture was introduced into the chamber that initially contained 1,010 ppmv methylene chloride, 1,020 ppmv TCA, 1,010 ppmv 1,1,2-trichloro-1,2,2-trifluoroethane (Freon-113), 301 ppmv carbon tetrachloride, and $297 \mathrm{ppmv}$ trichloroethylene (TCE) in hydrocarbon-free air. Another VOC-gas mixture containing 764 ppmv methanol, 980 ppmv TCA, 398 ppmv toluene, 746 ppmv cyclohexane, and 99 ppmv p-xylene in hydrocarbon-free air was also used.

4.2.1.1 NFT-020 Filter Vent. ${ }^{\mathrm{h}}$ Two sets of experiments were conducted to determine if VOC loading of the carbon-composite material significantly affected the rate of VOC transport through a filter vent. A VOC gas mixture was introduced into the test vessel through the fill port at an approximate rate of $1,000 \mathrm{~cm}^{3} \mathrm{~min}^{-1}$ for one minute to purge air out from the vessel. After the gas flow was discontinued, a clean filter was installed in the lid. The feed line was disconnected from the vessel and the feed port was capped. Gas samples were withdrawn by gas syringe at regular time intervals over 2 to 3 hours. Samples were injected into a gas chromatograph to determine VOC concentrations. In other tests, approximately one liter of VOC gas was introduced into a test vessel with the filter vent attached to the vessel. This procedure increased the amount of VOCs absorbed onto the carbon composite filter.

Hydrogen was introduced into a test vessel with a filter vent at about of $1,000 \mathrm{~cm}^{3} \mathrm{~min}^{-1}$ for a period of one minute to purge air out from the vessel. Samples were collected over 40 minutes. The $\mathrm{H}_{2}$ and VOC diffusion characteristics were determined for six filters. The room temperature during the tests was $298 \mathrm{~K}$ and the average ambient pressure was $64.4 \mathrm{~cm} \mathrm{Hg}$.

4.2.1.2 NFT-012 and NFT-013 Filter Vents. The gas mixture was introduced into a test vessel with filter vent attached through the fill port at about $1,000 \mathrm{~cm}^{3} \mathrm{~min}^{-1}$ for one minute to purge the vessel. The feed line was disconnected from the vessel and the feed port was capped. Gas samples were withdrawn by gas syringe at regular time intervals. Samples were injected into a gas chromatograph to determine gas concentrations. The room temperature during the tests was $298 \mathrm{~K}$ and the average ambient pressure was $64.4 \mathrm{~cm} \mathrm{Hg}$.

Total sample duration for the VOC gas mixtures was approximately 45 minutes. For the NFT-013 filter vents, only four accurate measurements of the $\mathrm{H}_{2}$ concentration in the test vessel could be obtained within the first 12 minutes. As a result, tests to determine the $\mathrm{H}_{2}$ diffusion.

h. Unpublished report concerning measurement and estimation of gas diffusion characteristic across NFT-020 drum filter vents; K. J. Liekhus and D. A. Johnson, EG\&G Idaho, Inc. (December 1993). 
characteristic were performed in triplicate for each filter vent. For NFT-012 filter vents, the turnaround time between samples was reduced, and six gas samples were collected during each test; thus, only one $\mathrm{H}_{2}$ diffusion test was performed for each filter vent.

\subsubsection{Polymer Bags}

Multivariable two-level experiments with one replicate were designed to investigate the effect of bag closure type on $\mathrm{H}_{2}$ and VOC transport from small polymer bags. Trichloroethylene and Freon-113 were used in the experiments. The process variables were the bag $(0.0076 \mathrm{~cm}$ ( 3 mil) polyethylene or $0.028 \mathrm{~cm}(11 \mathrm{mil}) \mathrm{PVC}$ ) and bag closure type (taped closure or heat-sealed). For each combination of bag and closure type, three bags were prepared. The bags were randomly distributed between the experiments and each bag was used twice. 


\section{RESULTS}

\subsection{Hydrogen Transport Characteristics}

The average and minimum $\mathrm{H}_{2}$ diffusion characteristics for each drum filter vent type are summarized in Table 1. The $\mathrm{H}_{2}$ transport characteristics for polyethylene and PVC bags with a heat-sealed or taped closure are listed in Table 2. A general linear regression model was used on the experimental data to determine that at a level of significance of $\alpha=0.05$, there was no significant difference in the $\mathrm{H}_{2}$ transport characteristic across polyethylene or PVC bags with different closure types.

\subsection{VOC Transport Characteristics}

In experiments using the NFT-020 filter vents, the natural logarithm of the fraction of the initial VOC concentration in the test vessel was plotted as a function of time. Linear regression analysis was performed on each set of data to identify the slope and the correlation coefficient. The correlation coefficient, in all cases, was greater than 0.98 . The VOC diffusion characteristics measured across six different clean and used filters are listed in Table 3. A students t-test at an $\alpha=0.05$ level of significance showed that the difference in VOC diffusion characteristics for clean and used filter vents was significant for all VOCs except Freon-113. This was attributed to VOCs being adsorbed onto the carbon-composite materials. As a result, all later experiments had filter vents in place on the test vessel during gas purging instead of being put in place after purging. The average diffusion characteristics of nine different VOCs for NFT-012 and NFT-013 filter vents using this procedure are listed in Table 4.

A statistical linear model analysis of VOC transport characteristic experimental data was performed to identify if the total transport characteristic varied significantly as result of the bag closure type. The bag closure type did not significantly affect the TCE transport rate from polymer bags. A bag material-bag closure interaction was observed with Freon-113. Specifically, the transport characteristic for PVC bags with a taped closure was significantly higher than for any other bag material-closure type combination.

Table 1. Average and minimum $\mathrm{H}_{2}$ diffusion characteristics $\left(\mathrm{mol} \mathrm{s} \mathrm{s}^{-1} \times 10^{7}\right.$ ) across different NFT drum filter vents.

\begin{tabular}{lcc}
\hline & Average & Minimum \\
\hline NFT-012 & $28 \pm 6^{\mathbf{a}}$ & 17 \\
NFT-013 & $117 \pm 11$ & 102 \\
NFT-020 & $42 \pm 1$ & 41 \\
a. One standard deviation. & & \\
\hline
\end{tabular}


Table 2. Hydrogen transport characteristics $\left(\mathrm{mol} \mathrm{s}^{-1} \times 10^{7}\right)$ for polyethylene and PVC bags.

\begin{tabular}{lcc} 
& Polyethylene & PVC \\
\cline { 2 - 3 } Twist-and-tape closure & 5.93 & 2.99 \\
& 6.76 & 1.98 \\
Heat-sealed closure & 3.65 & \\
& 8.72 & 1.99 \\
& & 2.09 \\
\hline
\end{tabular}

Table 3. VOC diffusion characteristics $\left(\mathrm{mol} \mathrm{s}^{-1} \times 10^{7}\right)$ for clean and used NFT-020 drum filter vents.

\begin{tabular}{lccccc}
\hline $\begin{array}{c}\text { Filter } \\
\text { ID number }\end{array}$ & $\begin{array}{c}\text { Methylene } \\
\text { chloride }\end{array}$ & Freon-113 & TCA & $\begin{array}{c}\text { Carbon } \\
\text { tetrachloride }\end{array}$ & TCE \\
\hline HC7: Clean & 3.75 & 2.74 & 2.87 & 2.85 & 3.32 \\
HC7: Used & 3.71 & 2.73 & 2.69 & 2.61 & 3.16 \\
JD8: Clean & 4.90 & 3.41 & 3.33 & 3.28 & 3.38 \\
JD8: Used & 4.75 & 3.64 & 3.39 & 3.08 & 3.27 \\
NB5: Clean & 4.84 & 3.69 & 3.54 & 3.39 & 3.37 \\
NB5: Used & 4.90 & 3.66 & 3.40 & 3.07 & 3.27 \\
IE8: Clean & 5.09 & 3.68 & 3.51 & 3.43 & 3.44 \\
IE8: Used & 4.44 & 3.59 & 3.38 & 3.24 & 3.43 \\
GD9:Clean & 5.11 & 3.72 & 3.62 & 3.49 & 3.68 \\
GD9: Used & 4.30 & 3.48 & 3.23 & 3.14 & 3.09 \\
OE4: Clean & 4.87 & 3.70 & 3.51 & 3.41 & 3.32 \\
OE4: Used & 4.44 & 3.43 & 3.14 & 3.02 & 286 \\
\hline
\end{tabular}


Table 4. VOC diffusion characteristic $\left(\mathrm{mol} \mathrm{s}^{-1} \times 10^{7}\right)$ for NFT-012 and NFT-013 drum filter vents.

\begin{tabular}{lll}
\hline & NFT-012 & NFT-013 \\
\hline Freon-113 & $3.20 \pm 0.51^{\mathrm{a}}$ & $10.4 \pm 0.6$ \\
Methylene chloride & $4.50 \pm 0.67$ & $17.7 \pm 0.9$ \\
1,1,1-trichloroethane ${ }^{\mathrm{b}}$ & $3.85 \pm 0.60$ & $10.4 \pm 0.5$ \\
1,1,1-trichloroethane ${ }^{\mathrm{c}}$ & $3.79 \pm 0.57$ & $11.0 \pm 0.6$ \\
Carbon tetrachloride & $3.83 \pm 0.57$ & $10.6 \pm 0.5$ \\
Trichloroethylene & $4.21 \pm 0.53$ & $13.9 \pm 1.8$ \\
Methanol & $6.00 \pm 1.11$ & $9.7 \pm 0.9$ \\
Cyclohexane & $4.00 \pm 0.59$ & $11.2 \pm 0.5$ \\
Toluene & $4.29 \pm 0.50$ & $13.2 \pm 2.5$ \\
p-xylene & $3.55 \pm 0.29$ & $11.7 \pm 2.3$ \\
& & \\
\hline a. One standard deviation. & & \\
b. Gas mixture containing TCA, Freon-113, TCE, carbon tetrachloride, and methylene chloride. \\
c. Gas mixture containing TCA, methanol, cyclohexane, toluene, and p-xylene.
\end{tabular}




\section{DISCUSSION}

\subsection{Drum Filter Vents}

\subsubsection{Hydrogen Diffusion Characteristic}

The $\mathrm{H}_{2}$ diffusion characteristics from this report and past investigations are summarized in Table 5 by the types of NFT drum filter vents. In all cases, values determined using the current INEL test vessel were greater than previously reported values. The higher values of $\mathrm{H}_{2}$ diffusion characteristic are attributed to the test vessel configuration, the position of the filter vent relative to the gas sample location, and the validity of assuming a well-mixed gas volume. The test vessel used in the new diffusion studies minimized the distance between the base of the filter vent and had an internal volume between 55 and $60 \mathrm{~cm}^{3}$. The lower diffusion characteristics in other small test vessels $\left(75-110 \mathrm{~cm}^{3}\right)$ are attributed to the elongated geometry of the test cylinder. Filter vents were located at the top usually attached to an adapter and gas samples were collected from the middle of the test vessel. The design of these test vessels increased the likelihood of developing a concentration gradient in or near the test vessel. The larger diffusion characteristic value reported by Liekhus ${ }^{d}$ was attributed to the fact that the $\mathrm{H}_{2}$ concentration outside the 4.33-L test vessel was also measured which resulted in a more accurate knowledge of the concentration gradient across the vent.

\subsubsection{VOC Diffusion Characteristic}

6.1.2.1 Clean and Used Filter Vents. The filter treatment procedure passed approximately $100 \%$ of the molar capacity of the carbon-composite media over the filter in one minute, although only a fraction of the VOCs adsorbed onto the filter. The VOC diffusion characteristics for treated filters were slightly less than values calculated for untreated filters. This was attributed to a decrease in the VOC-adsorption capacity of the filters. The adsorption capacity of a clean filter may have enhanced the VOC transport rate across the filter. Thus, a more conservative estimate of VOC diffusion characteristics requires that tests be performed across filters exposed to VOC gas mixture before gas sampling.

It was assumed that the diffusion characteristic for each VOC was not influenced by the presence of the other VOCs. Values for TCA diffusion characteristics using two different gas mixtures (see Table 4) indicates that this was a valid assumption.

6.1.2.2 Estimating VOC Diffusion Characteristic. It has been proposed that the ratio of the VOC-to- $\mathrm{H}_{2}$ diffusion characteristics is equal to the ratio of VOC-to- $\mathrm{H}_{2}$ diffusivity in air

$$
\frac{D^{*}{ }_{v o c}}{D^{*}{ }_{H_{2}}}=\frac{D_{v o c-a i r}}{D_{H_{2} \text {-air }}} \text {. }
$$

The VOC diffusion characteristic has been estimated using the hydrogen as a reference gas and the inverse ratio of molecular weights. ${ }^{1}$ Thus, the ratio of diffusion characteristics is 
Table 5. Comparison of reported $\mathrm{H}_{2}$ diffusion characteristics $\left(\mathrm{mol} \mathrm{s}^{-1} \times 10^{7}\right.$ ) for different drum filter vents.

\begin{tabular}{llll}
\hline & NFT-012 & NFT-013 & NFT-020 \\
\hline This report & $28 \pm 6^{\mathrm{a}}$ & $117 \pm 11$ & $42 \pm 1$ \\
Peterson $^{\mathrm{b}}$ & $23 \pm 2$ & - & $39 \pm 10$ \\
Peterson $^{\mathrm{c}}$ & - & 74 & - \\
Hobbs $^{\mathrm{d}}$, Liekhus $^{\mathrm{e}}$ & - & $105 \pm 3$ & - \\
McNew $^{\mathrm{f}}$ & - & - & $24 \pm 3$ \\
McNew $^{\mathrm{g}}$ & - & - & $40 \pm 2$ \\
Smith $^{\mathrm{h}}$ & - & $85 \pm 3$ & -
\end{tabular}

a. One standard deviation

b. Unpublished report, S. H. Peterson, Westinghouse R\&D Center (July 1988).

c. Unpublished report, S. H. Peterson and G. R. Marshall, Westinghouse R\&D Center (October 1990).

d. Unpublished report, D. T. Hobbs, Westinghouse Savannah River Corp. (July 1990).

e. Unpublished report, K. J. Liekhus and D. A. Johnson, EG\&G Idaho, Inc. (June 1994).

f. Unpublished report, E. B. McNew and D. A. Johnson, EG\&G Idaho, Inc. (April 1992).

g. Unpublished report, E. B. McNew, EG\&G Idaho, Inc. (June 1992).

h. Reference 5 .

estimated as

$$
\frac{D_{v o c-a i r}}{D_{H_{2} \text {-air }}}=\sqrt{\frac{M W_{H_{2}}}{M W_{v o c}}}
$$

Gas diffusivity in air can be estimated at low pressures using an equation developed from a combination of kinetic theory and corresponding-states arguments ${ }^{6}$

$D_{A B}=2.745 \times 10^{-4} \frac{T^{1.823}}{P}\left[p_{c A} p_{c B}\right]^{1 / 3}\left[T_{c A} T_{c B}\right]^{-1 / 2}\left[\frac{1}{M_{A}}+\frac{1}{M_{B}}\right]^{1 / 2}$ 
where

$$
\begin{aligned}
& D_{A B}=\text { mass diffusivity for gas(A)-gas(B) system, } \mathrm{cm}^{2} \mathrm{~s}^{-1} \\
& \mathrm{P}_{\mathrm{ci}}=\text { critical pressure of species } \mathrm{i} \text {, atm } \\
& \mathrm{T}_{\mathrm{ci}}=\text { critical temperature of species } \mathrm{i}, \mathrm{K} \\
& \mathrm{M}_{\mathrm{i}}=\text { molecular weight of species } \mathrm{i} .
\end{aligned}
$$

The ratio of VOC-to- $\mathrm{H}_{2}$ diffusivity in air can be estimated using Equation (10)

$$
\left[\frac{D_{v o c-a i r}}{D_{H_{2} \text {-air }}}\right]=\left[\frac{p_{c, v o c}}{p_{c, H_{2}}}\right]^{1 / 3}\left[\frac{T_{c, v o c}}{T_{c, H_{2}}}\right]^{-1 / 2}\left[\frac{\frac{1}{M_{a i r}}+\frac{1}{M_{v o c}}}{\frac{1}{M_{a i r}}+\frac{1}{M_{H_{2}}}}\right]^{1 / 2} .
$$

The experimental VOC-to- $\mathrm{H}_{2}$ diffusion characteristic ratios and estimated ratio values predicted using Equations (9) and (11) are listed in Table 6.

The VOC-to- $\mathrm{H}_{2}$ ratios for NFT-012 filter vents was greater than the corresponding ratios in the other filter vents. This phenomenon is attributed to the difference in the filter vent designs and highlights the limitation of using gas diffusivity data to estimate diffusion through porous media. The smaller openings at both ends of the NFT-012 filter vent result in decreased

Table 6. Experimental and estimated $\mathrm{VOC} / \mathrm{H}_{2}$ diffusion characteristic ratios.

\begin{tabular}{llllll}
\hline & NFT-012 & NFT-013 & NFT-020 & $\begin{array}{l}\text { Eqn } \\
(9)\end{array}$ & $\begin{array}{l}\text { Eqn } \\
(11)\end{array}$ \\
\hline Freon-113 & $0.116 \pm 0.014^{\mathrm{a}}$ & $0.089 \pm 0.005$ & $0.081 \pm 0.005$ & 0.104 & 0.100 \\
Methylene chloride & $0.163 \pm 0.020$ & $0.151 \pm 0.007$ & $0.104 \pm 0.010$ & 0.154 & 0.128 \\
1,1,1-trichloroethane & $0.139 \pm 0.016$ & $0.092 \pm 0.004$ & $0.093 \pm 0.007$ & 0.122 & 0.105 \\
Carbon tetrachloride & $0.139 \pm 0.017$ & $0.091 \pm 0.004$ & $0.071 \pm 0.005$ & 0.114 & 0.105 \\
Trichloroethylene & $0.152 \pm 0.015$ & $0.119 \pm 0.009$ & $0.075 \pm 0.005$ & 0.123 & 0.108 \\
Methanol & $0.218 \pm 0.028$ & $0.083 \pm 0.005$ & $0.142 \pm 0.033$ & 0.250 & 0.168 \\
Cyclohexane & $0.145 \pm 0.018$ & $0.096 \pm 0.005$ & $0.104 \pm 0.016$ & 0.154 & 0.108 \\
Toluene & $0.155 \pm 0.018$ & $0.113 \pm 0.011$ & $0.086 \pm 0.010$ & 0.147 & 0.104 \\
p-xylene & $0.129 \pm 0.014$ & $0.100 \pm 0.010$ & $0.059 \pm 0.009$ & 0.137 & 0.095
\end{tabular}

a. One standard deviation. 
diffusion rates for both hydrogen and the VOCs. However, the diffusion rate of the larger VOC molecules through the filter vent is more influenced by the carbon composite medium than $\mathrm{H}_{2}$. Thus, compared with the other filter vents, the vent constrictions cause a relative larger decrease in $\mathrm{H}_{2}$ diffusion characteristic than in the VOC diffusion characteristic, which results in an increase in the VOC-to- $\mathrm{H}_{2}$ ratio. A comparison of predicted diffusion characteristic ratios using Equations (9) and (11) indicate that Equation (9) predicts larger VOC-to- $\mathrm{H}_{2}$ ratios. Equation (9) was generally more accurate in estimating the ratio for NFT-012 vents. Equation (11) was generally more accurate in estimating the ratio for NFT-013 and NFT-020 filter vents. Neither equation adequately predicted the diffusion characteristic ratio for methanol across the filter vents. Methanol is difficult to analyze because of its propensity as a polar compound to adhere to surfaces.

\subsection{Polymer Bags}

In determining the best straight line fit of the VOC data for PVC bags, data taken in approximately the first 2.5 hours $(9,000 \mathrm{~s})$ were excluded. For hydrogen, data collected during the first $1,000 \mathrm{~s}$ were excluded. The nonlinear behavior over these times is attributed to the accumulation of gas in the polymer at the beginning of each trial. At the beginning of each trial, the polymer is relatively free of these compounds. During the course of the experiment, the gas content in the polymer approaches an equilibrium value. This equilibrium concentration may change during the experiment as the gas phase concentration in the void volume decreases, but the greatest rate of change occurs early in the experiment. For polyethylene bags, the data point at time zero was the only data excluded in the straight line fit for both $\mathrm{H}_{2}$ and the VOCs. Freon-113 and TCE may have different solubility in each polymer, but the main reason for different times over which data exhibits nonlinear behavior is attributed to the total mass of the bags. The mass of the PVC bag was nearly four times greater than that of the polyethylene bag.

The statistical test identified a bag material-closure type interaction in the bags containing Freon-113. Specifically, the transport characteristic from the PVC bags with a taped closure were significantly greater than from any other polymer-closure type combination. Several possibilities exist that may explain this discrepancy. The PVC bags are thicker and, thus, the taped closure may be more difficult to seal tightly. However, since $\mathrm{H}_{2}$ diffuses approximately an order of magnitude more quickly than the VOCs, $\mathrm{H}_{2}$ transport rate from the PVC bags with a taped closure should be significantly greater than from heat-sealed bags; this was not observed. This indicates that a pathway that allows significant vapor or gas diffusion does not exist. A more likely explanation is that Freon-113 accumulates in new PVC bags during the initial stage of the experiments while it permeates relatively slowly from the bags. Unlike the bag holding the gas, the polymer in the taped closure is not directly exposed to the VOC vapor and will take longer to achieve an equilibrium concentration. As a result, Freon-113 is steadily drawn up through the base of the taped closure. Since $\mathrm{H}_{2}$ has relatively low solubility in both polymers, the presence of the taped closure has a lesser effect on the total $\mathrm{H}_{2}$ transport rate.

Two other studies investigated $\mathrm{H}_{2}$ transport through PVC bags with heat-sealed and taped closures. ${ }^{1,5}$ The differences in total bag surface area, bag material, and bag thickness make it difficult to draw any conclusions from direct comparison of transport characteristics. Hydrogen permeability across a polymer can be calculated from the transport characteristic of the heat-sealed bags given the bag surface area, thickness, gas volume, temperature, and pressure. 
Assuming that the primary transport mechanism from heat-sealed bags is permeation and no pressure differential across the bag exists, the $\mathrm{H}_{2}$ permeability across polyethylene and PVC were calculated to be 10 and $12 \mathrm{Ba}\left(\mathrm{Ba}=10^{-10} \mathrm{~cm}^{3}(\mathrm{STP}) \mathrm{cm} \mathrm{cm}^{-2} \mathrm{~s}^{-1}(\mathrm{~cm} \mathrm{Hg})^{-1}\right)$, respectively. This compares with reported values of $10 \mathrm{Ba}$ across polyethylene and between 4 and $9 \mathrm{Ba}$ across PVC. ${ }^{7}$ Hydrogen permeabilities estimated from the $\mathrm{H}_{2}$ transport characteristics in the TRUPACT-II SAR ${ }^{1}$ and Smith et al..$^{5}$ were 9 and $14 \mathrm{Ba}$, respectively.

Comparison of the ratio of transport characteristics from taped closure and heat-sealed bags with similar bag thickness and surface area eliminates most of the effect of these variables. The ratios of the average $\mathrm{H}_{2}$ transport characteristics from this report and two earlier investigations are listed in Table 7. The ratio of transport characteristics for polymers determined in unsteadystate experiments indicates that an increase in the overall transport characteristic resulting from the presence of a taped closure is not significant. This conclusion is different from that made from the steady-state experiment. ${ }^{1}$ In the steady-state tests, the $\mathrm{H}_{2}$ transport characteristic across the taped closure was determined as the difference between transport characteristics measured across similar PVC bags with and without a taped closure. The original data showed the $\mathrm{H}_{2}$ concentration in the polymer bag with a taped closure was increasing during the final 12-hour period and was not at steady state. ${ }^{1}$ Hydrogen gas flow was also not maintained at a constant rate, but continuously adjusted to maintain $\mathrm{H}_{2}$ concentration at $4 \%$. In addition, duplicate tests were not performed. In contrast, the unsteady-state experiment described in this report included tests across two different bags of the same material and closure type to calculate the average $\mathrm{H}_{2}$ transport characteristic. Under these conditions, $\mathrm{H}_{2}$ transport from small polymer bags was not significantly affected by the type of bag closure. This means that most small bags placed in vented waste drums could have either a taped closure or heat seal without significantly affecting $\mathrm{H}_{2}$ transport from the bags.

Table 7. Ratio of average $\mathrm{H}_{2}$ transport characteristic for bags with taped closures to average $\mathrm{H}_{2}$ transport characteristic for heat-sealed bags.

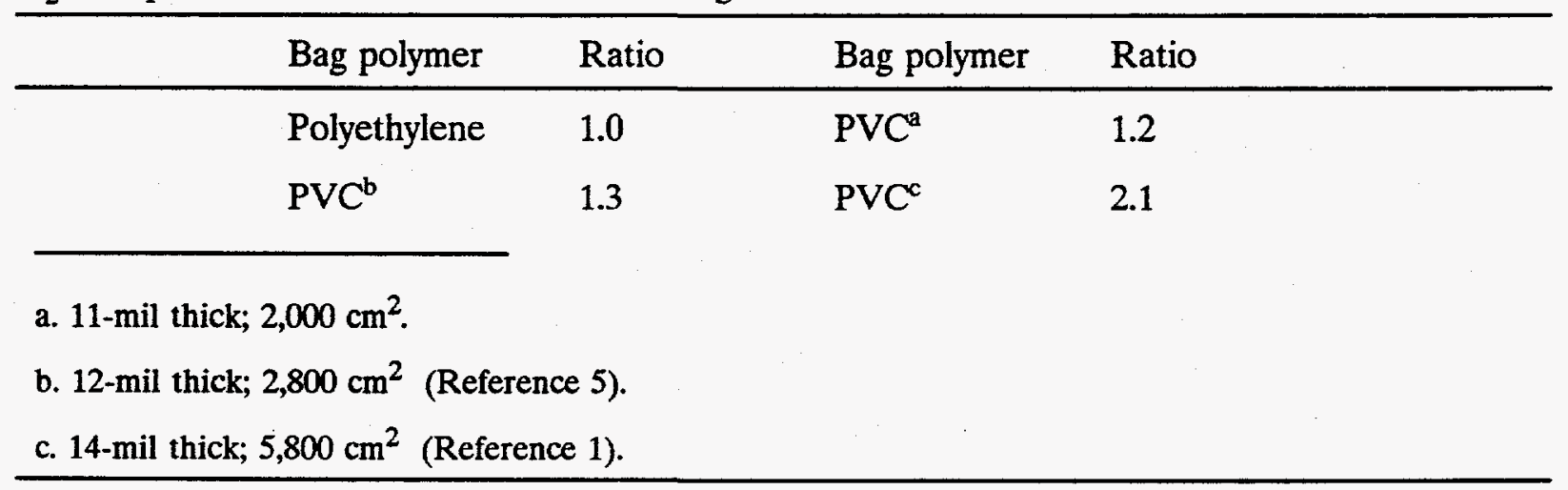




\section{IMPACT OF TRANSPORT CHARACTERISTICS ON MODEL CALCULATIONS}

The impact of different $\mathrm{H}_{2}$ and VOC transport characteristics for filter vents and polymer bags used in earlier model calculations is discussed in this section.

\subsection{Hydrogen Transport Characteristics}

Test results showed that the configuration of the test vessel affects the calculated filter vent gas diffusion characteristic. Hydrogen diffusion characteristics calculated from experimental data using the INEL test vessels were about 10 to $25 \%$ greater than the highest previously reported values. A larger diffusion characteristic would result in higher minimum allowable decay heat limit. A hydrogen diffusion characteristic of $19 \times 10^{-7} \mathrm{~mol} \mathrm{~s}^{-1}$ was used to calculate the maximum allowable decay heat limit per innermost layer of confinement in the TRUPACT-II SAR. ${ }^{1}$ This value was the lowest value determined across six NFT-012 filters. However, NFT-012 filter vents are no longer used in the transportation of vented waste drums. The NFT-013 and NFT-020 filter vents are used. The lowest $\mathrm{H}_{2}$ diffusion characteristic measured across these filter vents using the smaller INEL test vessel was $41 \times 10^{-7} \mathrm{~mol} \mathrm{~s}^{-1}$. The use of a $\mathrm{H}_{2}$ diffusion characteristic of a different drum filter vent will have a far more significant impact on model results than higher values resulting from improved test vessel design and experimental procedure.

In model calculations of the maximum allowable decay heat limit per layer of confinement, ${ }^{1}$ a $\mathrm{H}_{2}$ transport characteristic of $5.60 \times 10^{-7} \mathrm{~mol} \mathrm{~s}^{-1}$ was used as a conservative estimate of gas transport from a polymer bag with a taped closure. This value was the difference of two $\mathrm{H}_{2}$ transport characteristics measured across PVC bags with and without taped closures, and was meant to describe $\mathrm{H}_{2}$ transport through the taped closure. Experimental evidence indicates that the transport characteristic for at least one bag was not measured under steady-state conditions as assumed. In addition, two unsteady-state experiments demonstrated that total $\mathrm{H}_{2}$ transport across a small PVC bag with a taped closure is not significantly greater than a similarly sized PVC bag with no taped closure. As a result, the maximum allowable decay heat limit should have been calculated using a $\mathrm{H}_{2}$ permeation characteristic for a heat-sealed PVC bag. The $\mathrm{H}_{2}$ permeation characteristic for a heat-sealed PVC bag reported in the TRUPACT-II SAR was $4.94 \times 10^{-7} \mathrm{~mol} \mathrm{~s}^{-1}{ }^{1}$. This transport characteristic is $12 \%$ less than the value used in original calculations and would result in a slightly lower calculated decay heat limit, all other variables remaining the same. In this report, the average $\mathrm{H}_{2}$ permeation characteristic for heat-sealed PVC bags was $2.04 \times 10^{-7} \mathrm{~mol} \mathrm{~s}^{-1}$ and is less than the transport characteristic reported in the TRUPACT-II SAR because of smaller bag surface area.

\subsection{VOC-Filter Vent Diffusion Characteristic}

The VOC diffusion characteristic across a filter vent is used in the WIPP NMD variance petition $^{2}$ to estimate the rate of VOC emissions from a vented drum. The diffusion characteristics for carbon tetrachloride and TCA across different drum filter vent types are on the order of $10^{-11} \mathrm{~mol} \mathrm{~s}^{-1}$. It was estimated that rate of TCA emissions from a waste drum containing waste form Benelex/Plexiglass was $3.2 \times 10^{-14} \mathrm{~mol} \mathrm{~s}^{-1}$. The explanation for the lower than expected values was a complex combination of FIckian and surface diffusion. A more likely explanation is 
that the experimental set-up resulted in significant concentration gradient across the test vessel volume. Peterson and Marshall ${ }^{b}$ and this report demonstrated that actual VOC diffusion characteristics are on the order of $10^{-7} \mathrm{~mol} \mathrm{~s}^{-1}$. Using the same TCA headspace concentration from a drum containing waste form Benelex/Plexiglass, the TCA emission rate from a drum with a NFT-012 filter vent is $1.0 \times 10^{-9} \mathrm{~mol} \mathrm{~s}^{-1}$. This is over four orders of magnitude greater and significantly changes the total anticipated VOC emissions from vented waste drums at the WIPP facility. The rate of VOC emissions will still decrease as the VOC drum headspace concentration decreases. 


\section{CONCLUSIONS}

1. Higher $\mathrm{H}_{2}$ and VOC diffusion characteristics for NFT drum filter vents were calculated using the INEL test vessels than measured in earlier experiments. The higher values are considered to be more accurate because of the small test vessel volume and the vessel configuration specifically designed to minimize concentration gradient formation.

2. Tests on PVC bags with a surface area between 2,000 and $3,000 \mathrm{~cm}^{2}$ and bag thickness between 2.8 and $3.0 \times 10^{-2} \mathrm{~cm}\left(11-12\right.$ mil) show that the $\mathrm{H}_{2}$ transport characteristic from bags with a taped closure was only 20 to $30 \%$ greater than from heat-sealed bags. Tests on polyethylene bags with a surface area of $2,000 \mathrm{~cm}^{2}$ and bag thickness of $7.6 \times 10^{-3} \mathrm{~cm}(3 \mathrm{mil})$ showed no difference at all in the $\mathrm{H}_{2}$ transport characteristic for bags with different types of closure. Under these conditions, $\mathrm{H}_{2}$ transport from small polymer bags was not significantly affected by the type of bag closure. This means that most small bags placed in vented waste drums could have either a taped closure or heat seal without significantly affecting $\mathrm{H}_{2}$ transport from the bags.

3. Gas transport from polyethylene or PVC bags containing TCE or Freon-113, or other VOCs with similar permeability across the polymer, would not be significantly affected by bag closure type in actual waste drums.

4. Two methods of estimating a VOC diffusion characteristic across a filter vent based on the measured $\mathrm{H}_{2}$ diffusion characteristic and the estimated ratio of VOC-air diffusivity to hydrogen-air diffusivity were examined. The method estimating the ratio by the square root of the $\mathrm{H}_{2}$-to-VOC molecular weight ratio was best for NFT-012 drum filter vents. The method estimating the ratio using the critical temperature and pressure of $\mathrm{H}_{2}$ and the VOC as well as the molecular weight of $\mathrm{H}_{2}$, VOC, and air was a better method for NFT-013 and NFT-020 drum filter vents.

5. Direct comparison of $\mathrm{H}_{2}$ permeation characteristics measured in different experiments is difficult because the transport characteristic is a function of the total permeable surface area, bag thickness, and gas-polymer permeability. Instead, hydrogen-PVC permeabilities were: estimated from hydrogen permeation characteristics for heat-sealed PVC bags from the INEL and earlier transport experiments, and were approximately equal.

6. The $\mathrm{H}_{2}$ transport characteristic for a PVC bag with a taped closure reported in the TRUPACT-II SAR ${ }^{1}$ was based on flawed experimental data. Steady-state conditions were assumed despite evidence that steady state had not been achieved. This led to the incorrect conclusion that significant gas transport occurred through the taped closure.

7. The $\mathrm{H}_{2}$ permeation characteristic reported in the TRUPACT-II SAR for the heat-sealed PVC bag should have been used in model calculations of the maximum allowable decay heat limit per layer of confinement, instead of the $\mathrm{H}_{2}$ transport characteristic reported for a taped closure of a PVC bag. This would have resulted in a slightly smaller calculated maximum allowable decay heat limit per innermost layer of confinement. 
8. Model calculations of the maximum allowable decay heat limit per layer of confinement in the TRUPACT-II SAR used the minimum $\mathrm{H}_{2}$ diffusion characteristic across a NFT-012 drum filter vent. The NFT-012 drum filter vent is no longer used in the transshipment of waste drums. The minimum $\mathrm{H}_{2}$ diffusion characteristic across a NFT-020 filter vent should now be used in calculating the maximum allowable decay heat limit per innermost layer of confinement. The average $\mathrm{H}_{2}$ diffusion characteristic across the NFT-020 filter vent is over two times greater than the NFT-012 value used in original calculations. This will result in an increase in the maximum allowable decay heat limit per innermost layer of confinement.

9. The VOC diffusion characteristics used in the WIPP NMD Variance Petition to estimate the rate of VOC emissions from a vented drum were too low as a result of flawed experimental set-up. The VOC diffusion characteristics across different NFT filter vents were found to be at least four orders of magnitude greater than values listed in the WIPP NMD Variance Petetion. This significantly changes the total anticipated VOC emissions from vented waste drums at the WIPP facility. 


\section{REFERENCES}

1. Safety Analysis Report for the TRUPACT-II Shipping Package, Rev. 12, Nuclear Packaging, Inc., September 1992.

2. Waste Isolation Pilot Plant No-Migration Variance Petition, Vol. 1, DOE/WIPP 89-003, Rev. 1, Westinghouse Electric Corp., March 1990.

3. K. J. Liekhus, G. L. Gresham, E. S. Peterson, C. Rae, N. J. Hotz, and M. J. Connolly, Modeling Unsteady-state VOC Transport in Simulated Waste Drums, EGG-WM-10823, Rev. 1, EG\&G Idaho, Inc., 1994.

4. K. J. Liekhus, G. L. Gresham, C. Rae, and M. J. Connolly, VOC Transport in Vented Drums Containing Simulated Waste Sludge, EGG-WM-11205, EG\&G Idaho, Inc., 1994.

5. M. C. Smith, et al., Hydrogen generation and release in stored ${ }^{238} \mathrm{Pu}$ waste at Los Alamos National Laboratory. Health Physics Society 27th Midyear Meeting, Albany, NY, February 1994.

6. R. B. Bird, W. E. Stewart, and E. N. Lightfoot, Transport Phenomena, John Wiley: New York, 1960.

7. H. Yasuda and V. Stannett, in Polymer Handbook, 2nd edition, J. Brandup and E.H. Immergut (eds.), John Wiley: New York, 1975. 